\title{
Grape ASR-Silencing Sways Nuclear Proteome, Histone Marks and Interplay of Intrinsically Disordered Proteins
}

\author{
Hristo Atanassov ${ }^{1,2}$, Jonathan Parrilla ${ }^{1}$, Caroline Artault ${ }^{1}$, Jérémy Verbeke ${ }^{1,+}$, Thomas Schneider ${ }^{3, \ddagger}$, \\ Jonas Grossmann ${ }^{4}$, Bernd Roschitzki ${ }^{4}$ (D) and Rossitza Atanassova ${ }^{1, *(D)}$
}

1 UMR CNRS 7267 Écologie \& Biologie des Interactions, Équipe, Sucres \& Echanges Végétaux-Environnement, Université de Poitiers, 3 Rue Jacques Fort, 86073 Poitiers, France; hristo.atanassov@univ-poitiers.fr (H.A.); jonathan_parrilla@outlook.fr (J.P.); caroline.artault@univ-poitiers.fr (C.A.); jeremy.verbeke@uca.fr (J.V.)

2 CHU de Poitiers, 2 Rue de la Milétrie, 86021 Poitiers, France

3 Institute of Plant Biology, University of Zurich, Zollikerstrasse 107, 8008 Zurich, Switzerland; thomas.schneider@biognosys.com

4 Functional Genomics Center Zurich, University of Zurich and ETH Zurich, Winterthurerstrasse 190, 8057 Zurich, Switzerland; jg@fgcz.ethz.ch (J.G.); bernd.roschitzki@fgcz.uzh.ch (B.R.)

* Correspondence: rossitza.atanassova@univ-poitiers.fr

† Present address: Faculté de Médecine, GReD UMR CNRS 6293-INSERM U1103 Université Clermont-Auvergne, CRBC, 28 Place Henri Dunant, 63001 Clermont-Ferrand, France.

$\ddagger$ Present address: Biognosys AG, Wagistrasse 21, 8952 Schlieren, Switzerland.

check for

updates

Citation: Atanassov, H.; Parrilla, J.; Artault, C.; Verbeke, J.; Schneider, T.; Grossmann, J.; Roschitzki, B.; Atanassova, R. Grape ASR-Silencing Sways Nuclear Proteome, Histone Marks and Interplay of Intrinsically Disordered Proteins. Int. J. Mol. Sci. 2022, 23, 1537. https://doi.org/ $10.3390 /$ ijms 23031537

Academic Editor: Fabrizio Grassi

Received: 21 December 2021

Accepted: 26 January 2022

Published: 28 January 2022

Publisher's Note: MDPI stays neutral with regard to jurisdictional claims in published maps and institutional affiliations.

Copyright: (C) 2022 by the authors. Licensee MDPI, Basel, Switzerland. This article is an open access article distributed under the terms and conditions of the Creative Commons Attribution (CC BY) license (https:// creativecommons.org/licenses/by/ $4.0 /)$.

\begin{abstract}
In order to unravel the functions of ASR (Abscisic acid, Stress, Ripening-induced) proteins in the nucleus, we created a new model of genetically transformed grape embryogenic cells by RNAi-knockdown of grape ASR (VvMSA). Nuclear proteomes of wild-type and VvMSA-RNAi grape cell lines were analyzed by quantitative isobaric tagging (iTRAQ 8-plex). The most significantly up- or down-regulated nuclear proteins were involved in epigenetic regulation, DNA replication/repair, transcription, mRNA splicing/stability/editing, rRNA processing/biogenesis, metabolism, cell division/differentiation and stress responses. The spectacular up-regulation in VvMSA-silenced cells was that of the stress response protein VvLEA D-29 (Late Embryogenesis Abundant). Both VvMSA and VvLEA D-29 genes displayed strong and contrasted responsiveness to auxin depletion, repression of $V v M S A$ and induction of $V v L E A D-29$. In silico analysis of VvMSA and VvLEA D-29 proteins highlighted their intrinsically disordered nature and possible compensatory relationship. Semi-quantitative evaluation by medium-throughput immunoblotting of eighteen posttranslational modifications of histones $\mathrm{H} 3$ and $\mathrm{H} 4$ in VvMSA-knockdown cells showed significant enrichment/depletion of the histone marks H3K4me1, H3K4me3, H3K9me1, H3K9me2, H3K36me2, H3K36me3 and H4K16ac. We demonstrate that grape ASR repression differentially affects members of complex nucleoprotein structures and may not only act as molecular chaperone/transcription factor, but also participates in plant responses to developmental and environmental cues through epigenetic mechanisms.
\end{abstract}

Keywords: ASR; grape embryogenic cells; histone PTMs; IDPs; iTRAQ; LEA D-29; nuclear proteome; VvMSA-RNAi silencing

\section{Introduction}

Plant ASRs (Abscissic acid, Stress, Ripening proteins) have been discovered in tomato, as induced by water deficit in leaves and by ripening in fruit [1]. Identification of a plethora of ASRs in a multitude of higher plant species, gymnosperms and angiosperms (monocots and dicots), has confirmed their involvement in different stages of development (seed germination, flowering interval between female and male organs maturation, pollen desiccation, leaf senescence, fruit ripening), and in response to environmental cues (water, cold, salt and osmotic stresses, heavy metal and pesticide toxicity, and fungal diseases [2-10]. 
At a cellular level, ASR proteins have been localized both in cytoplasm and in the nucleus, which is due to the presence or the absence of a functional nuclear localization signal [11-15]. This dual subcellular location appears as a prerequisite for their functional duality. In fact, they supposedly act as molecular chaperones directly protecting biological macromolecules under stress, and noncanonical transcription factors in complexes for gene expression regulation [11,13]. It has been shown that ASRs, as highly hydrophilic proteins, display the ability to maintain certain enzymatic activities, such as those of lactate dehydrogenase and malate dehydrogenase, after several freeze/thaw cycles [16] and heat treatment [17]. In this regard, the heterologous overexpression of tomato ASR1 in potato has suggested its possible involvement in the regulation of glucose metabolism and carbon reallocation [18]. Furthermore, the antisense repression of SIASR1 in transgenic tobacco plants has clearly demonstrated a decrease in $\mathrm{CO}_{2}$ assimilation, increased diurnal accumulation of glucose in leaves concomitant with a significant reduction of sucrose in phloem sap, and diminished expression of hexose transporter HT1 and sucrose transporter SUT2 [19].

The grape ASR, VvMSA, has been identified as directly involved in gene expression regulation of the glucose transporter VvHT1, at the convergence of sugar and abscisic acid signaling pathways [11]. A model of the fine-tuning of VvMSA transcription regulation at promoter level by glucose and ABA has been built through the interplay of Hexokinase 1 (HXK1) and Sucrose-nonfermenting Related Kinase 1 (SnRK1) [20]. The role of ASRs at the interface of sugar metabolism and hormone signal transduction pathways, as well as their impact on the control of plant growth, development and response to environmental constraints, has been reported $[19,21]$.

ASRs have been classified as the seventh group of the large family of LEAPs (Late Embriogenesis Abundant Proteins), themselves belonging to the Dehydrins superfamily [22]. Four ASRs_tomato SlASR1, plantain MpASR, barley HvASR and wheat TtASR_have been considered Intrinsically Disordered Proteins (IDPs) [23-25]. Previously, it has been reported that IDPs lack a well-defined structure in their native state and under physiological conditions in the absence of a partner, in terms of protein/protein or protein/nucleic acid interactions [26-30]. Tomato SIASR1 has been demonstrated to adopt ordered conformation in the presence of $\mathrm{Zn}^{2+}$, thereby favoring its fixation to DNA [12]. Moreover, SIASR1 has been involved in the formation of homodimers and homotrimers capable of interacting with DNA [14,31]. The grape ASR belongs to the histone nucleosomal fraction of nuclear proteins and is entangled in a protein heterodimer with VvDREB, an APETALA2 transcription factor (TF), thus acting as a cofactor of architectural type involved in the recruitment of another canonical TF within a complex for transcriptional regulation [32]. Very recently, this finding has been corroborated by the demonstration that Brachipodium distachyon BdASR1 is able to interact with another member of the same APETALA2/Ethylene Responsive Factor (AP2/ERF) superfamily, the BdERF 96, in the plant response to drought and oxidative stresses [33]. In addition, several genes have been revealed as direct ASR targets by chromatin immunoprecipitation-based sequencing (ChIP-seq) using antibodies to tomato SlASR1 [34] and banana MaASR overexpressed in Arabidopsis [35]. In rice, an ASR (OsASR5) has been found to be involved in the regulation of a microRNA gene expression, i.e., osa-MIR167a [36].

Despite experimental evidence provided by different approaches for studying the interactions of ASR proteins with DNA (gel shift assay, yeast one-hybrid screening, in planta co-expression experiments, ChIP-seq) in tomato, grapevine, rice $[11,15,37,38]$ and with other nuclear proteins [32,33], the precise biological roles of ASR proteins in the nucleus remain elusive and necessitate further elucidation.

To shed more light on this issue, we succeeded in the genetic transformation of embryogenic grape cells and the RNAi-silencing of $V v M S A$, and used this model to compare the nuclear proteome of wild-type cells expressing the grape ASR, and VvMSA-RNAisilenced cells. To that aim, we performed eight-plex iTRAQ (isobaric Tag for Relative and Absolute Quantification) of proteins differentially extracted from isolated nuclei. The 
$V v M S A$-silencing significantly affected the expression level of 146 nuclear proteins involved in epigenetic, transcriptional, post-transcriptional and translational control of plant responses to developmental and environmental cues. The remarkable induction of one LEA protein in the absence of VvMSA, and their antagonistic relationship under auxin depletion in grape embryogenic cells, confirmed the interplay between these IDPs. To further explore the impact of VvMSA silencing on epigenetic landscape, we developed custom medium-throughput immunoblotting assay of multiplex type, applied at the level of total chromatin, and revealed significant quantitative changes in several $\mathrm{H} 3$ and $\mathrm{H} 4$ histone post-translational modifications in the absence of grape ASR.

\section{Results}

\subsection{Nuclear Proteome of Grape Wild-Type and VvMSA-RNAi-Silenced Cells}

Three fully independent transformation experiments were carried out on grape embryogenic cells 41B, at three different time periods and by three manipulators, using exactly the same protocol for genetic transformation. $V v M S A$ silencing in the three transgenic cell lines was tested by real-time qPCR (Figure 1A), which confirmed the successful RNAinterference knockdown of this grape ASR. It is worth noting that VvMSA repression in 41B embryogenic cells affected neither cell morphology (Figure 1B), proliferation capacity (Figure 1C), nor their differentiation ability for somatic embryogenesis, which was confirmed by the regeneration of VvMSA-RNAi silenced plantlets (Figure S1).
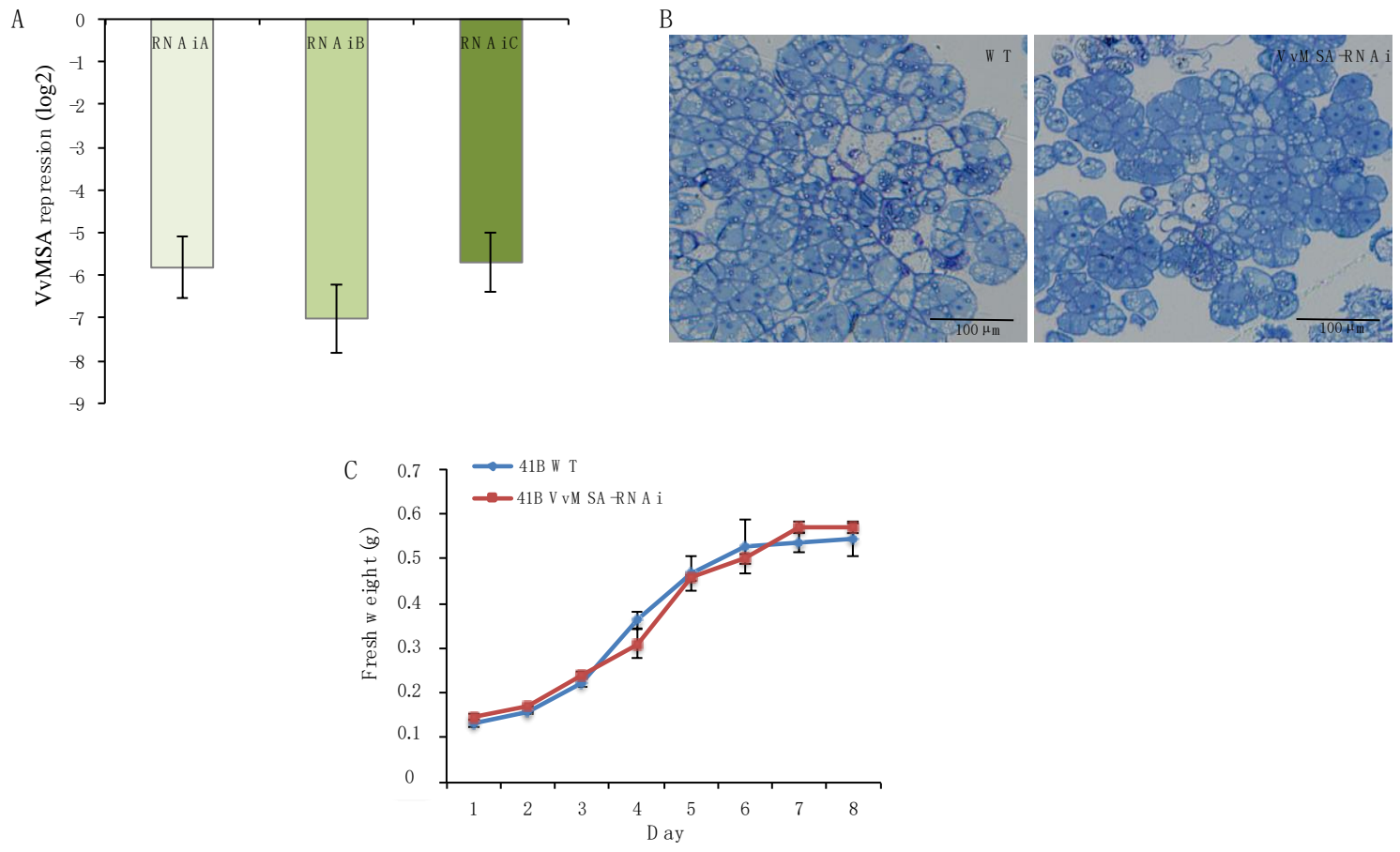

Figure 1. Phenotypic characterization of grape embryogenic 41B cells: wild-type and $V v M S A-R N A i$. (A) Real-time qPCR analysis of the grape ASR gene repression in three independent $V v M S A$-RNAi transgenic lines. The expression of each $V v M S A-R N A i$ line was reported to that of the control wild-type cells (previously normalized to the reference $V v A C T$ gene). The repression of $V v M S A$ was calculated by the $2^{-\Delta \Delta C t}$ method, and presented as $\log 2$ fold change. The results correspond to the mean value and the standard error of three biological replicates for each cell line. (B) Cell morphology observation by light microscopy after toluidine blue staining (Olympus DP72): wild-type (left) and $V v M S A-R N A i$ (right)). (C) Growth curves of wild-type cells (blue line) and VvMSA-RNAi transgenic cells (red line).

The originality of this cellular model consists in the homogeneity and the relative synchronization of the grapevine embryogenic cell population, thus circumventing one of the most critical problems in proteomic and epigenetic investigations due to plant cell 
heterogeneity within tissues. Consequently, transgenic versus wild-type embryogenic cells were chosen as a new model for studying ASR impact on nuclear proteome and histone epigenetic marks.

As far as we know, our study reports nuclear proteome analysis in grape for the first time. One of the features of iTRAQ is that this technology allows quantitative comparison of proteins, which must be present in both studied conditions. This explains why in our experiments VvMSA could not be identified by iTRAQ in the VvMSA-silenced cells, even though it is expressed in the wild-type cells.

Among all identified 484 nuclear proteins, 447 were successfully annotated in grapevine and only 37 remained with unknown function. A total of 146 proteins out of 484 displaying a 1.2-fold change and Q-value $>0.05$ were selected as differentially expressed proteins (DEPs) between wild-type and VvMSA-RNAi silenced cells (Table 1). These 146 proteins with significant differential expression encompassed 137 up-regulated and 9 down-regulated in $V v M S A-R N A i$ versus wild-type.

We first annotated the DEPs using BLAST to search for significant sequence homology and Uniprot to unravel conserved functional domains. As shown in Table 1, this approach allowed us to classify the proteins in eight functional groups: (1) cell division and differentiation $(n=11)$; (2) DNA replication and repair $(n=5)$; (3) epigenetic regulation $(n=29)$; (4) metabolism $(n=13)$; (5) mRNA splicing, stability and editing $(n=42) ;(6)$ rRNA processing and biogenesis $(n=13)$; (7) stress response $(n=13)$; $(8)$ transcriptional regulation $(n=20)$.

The sequences of the DEPs were also submitted to functional enrichment analysis for protein-protein interactions using the network's STRING database. This analysis suggested that 142 out of the 146 grape proteins could interact with other protein partners.

Gene Ontology (GO) enrichment analysis of the DEPs provided more details for their localization as cellular components (Figure 2), molecular functions (Figure 3), and involvement in biological processes (Figure S2). The latter classification turned out to be particularly exhaustive, suggesting involvement in more than hundred biological processes (Figure S2). The classification by cellular components confirmed the annotated DEPS as nuclear proteins, their localization in distinct nuclear subdomains, nucleoprotein- and protein-protein complexes (Figure 2). Interestingly, the most concise GO classification was generated when using the criterion of molecular function: only twelve molecular functions were suggested so far, mainly of DNA, RNA and cyclic compound binding, as well as of catalytic and transferase activity (Figure 3).

Table 1. Differentially expressed proteins in wild-type and VvMSA-RNAi grape embryogenic cells.

\begin{tabular}{lllll}
\hline \multicolumn{1}{c}{ UniProtKB Accession } & NCBI Accession & STRING Accession & Protein Function & $\begin{array}{c}\text { VvMSA-RNAi } \\
\text { vs. WT }\end{array}$ \\
\hline Cell division/Differentiation (n = 11) & & & Protein FLX-like 2 & 1.78 \\
\hline F6GVS4 (F6GVS4_VITVI) & CBI16879.3 & VIT_14s0083g00450.t01 & Procic single-stranded & 1.24 \\
\hline D7TD96 (D7TD96_VITVI) & CBI28469.3 & VIT_12s0057g01280.t01 & $\begin{array}{l}\text { G-strand specific } \\
\text { telomere-binding protein 2 }\end{array}$ & 1.24 \\
\hline F6HCE0 (F6HCE0_VITVI) & CBI25499.3 & VIT_13s0067g00550.t01 & Clathrin light chain 2-like & 1.28 \\
\hline D7T0X4 (D7T0X4_VITVI) & CBI24194.3 & VIT_19s0085g00200.t01 & Stigma/style cell cycle inhibitor 1 \\
\hline F6H9W8 (F6H9W8_VITVI) & CBI22388.3 & VIT_19s0085g00220.t01 & Cell division cycle 5-like protein & 1.22 \\
\hline D7SJS1 (D7SJS1_VITVI) & CBI15897.3 & VIT_06s0004g07170.t01 & $\begin{array}{l}\text { Structural maintenance of } \\
\text { chromosomes } \\
\text { domain-containing protein }\end{array}$ & $\begin{array}{l}\text { Sister chromatid cohesion } \\
\text { protein PDS5 homolog B }\end{array}$ \\
\hline F6GZE1 (F6GZE1_VITVI) & CBI18813.3 & VIT_00s0920g00020.t01 & 1.28 \\
\hline
\end{tabular}


Table 1. Cont.

\begin{tabular}{|c|c|c|c|c|}
\hline UniProtKB Accession & NCBI Accession & STRING Accession & Protein Function & $\begin{array}{l}V v M S A-\mathrm{RNAi} \\
\text { vs. WT }\end{array}$ \\
\hline D7U294 (D7U294_VITVI) & CBI36860.3 & VIT_07s0005g00470.t01 & Peter Pan-like protein & 0.38 \\
\hline D7SJV2 (D7SJV2_VITVI) & CBI15928.3 & VIT_06s0004g06870.t01 & $\begin{array}{l}\text { Proliferation-associated } \\
\text { protein } 2 \mathrm{G} 4 \text {-like }\end{array}$ & 0.33 \\
\hline D7T8K7 (D7T8K7_VITVI) & CBI26828.3 & VIT_01s0011g05790.t01 & $\begin{array}{l}\text { Microtubule-associated } \\
\text { protein } 70-2\end{array}$ & 1.71 \\
\hline F6HJS7 (F6HJS7_VITVI) & CBI29537.3 & VIT_00s0527g00030.t01 & $\begin{array}{l}\text { Pistil-specific extensin- } \\
\text { like protein-like }\end{array}$ & 1.78 \\
\hline \multicolumn{5}{|c|}{ DNA replication/Repair $(n=5)$} \\
\hline F6HAC8 (F6HAC8_VITVI) & CBI24290.3 & VIT_06s0009g02520.t01 & Replication factor C subunit 1-like & 1.25 \\
\hline D7TIQ6 (D7TIQ6_VITVI) & CBI30132.3 & VIT_08s0007g05120.t01 & DNA gyrase subunit B & 0.76 \\
\hline D7SH27 (D7SH27_VITVI) & CBI15707.3 & VIT_17s0000g00910.t01 & $\begin{array}{l}\text { Histidine kinase-, DNA gyrase B-, } \\
\text { and HSP90-like ATPase family }\end{array}$ & 1.27 \\
\hline D7TDE2 (D7TDE2_VITVI) & CBI34931.3 & VIT_01s0127g00840.t01 & $\begin{array}{l}\text { OB-fold nucleic acid binding } \\
\text { domain containing protein }\end{array}$ & 1.33 \\
\hline F6HSF7 (F6HSF7_VITVI) & CBI33677.3 & VIT_14s0006g03280.t01 & $\begin{array}{l}\text { DNA double-strand break repair } \\
\text { rad50 ATPase }\end{array}$ & 1.48 \\
\hline \multicolumn{5}{|l|}{ Epigenetic regulation $(n=29)$} \\
\hline E0CRG0 (E0CRG0_VITVI) & CBI19114.3 & VIT_18s0001g04770.t01 & $\begin{array}{l}\text { Apoptotic chromatin condensation } \\
\text { inducer in the nucleus }\end{array}$ & 0.71 \\
\hline A5BH86 (A5BH86_VITVI) & CВI30396.3 & VIT_08s0007g02200.t01 & $\begin{array}{l}\text { High mobility group B protein } 1 \\
\text { isoform } X 2\end{array}$ & 1.50 \\
\hline F6HUL8 (F6HUL8_VITVI) & CBI34365.3 & VIT_02s0025g00090.t01 & RNA-binding protein C25G10.01 & 1.53 \\
\hline D7T3I0 (D7T3I0_VITVI) & CBI25061.3 & VIT_00s0179g00340.t01 & Histone H2A.1 & 1.71 \\
\hline F6GV41 (F6GV41_VITVI) & CBI16181.3 & VIT_06s0004g04230.t01 & Histone H2B & 1.74 \\
\hline D7U2L4 (D7U2L4_VITVI) & CBI36980.3 & VIT_07s0005g01810.t01 & Agenet domain-containing protein & 1.87 \\
\hline D7TCM4 (D7TCM4_VIT & CBI27882.3 & VIT_11s0016g01890.t01 & Single myb histone & 1.33 \\
\hline D7TED8 (D7TED8_VITVI) & CBI28861.3 & VIT_12s0059g01310.t01 & SUMO protein & 1.43 \\
\hline D7TUZ2 (D7TUZ2_VITVI) & CBI34317.3 & VIT_14s0030g00480.t01 & $\begin{array}{l}\text { RNA recognition motif } \\
\text { family protein }\end{array}$ & 1.26 \\
\hline D7SIC8 (D7SIC8_VITVI) & CBI15238.3 & VIT_17s0000g06030.t01 & $\begin{array}{l}\text { Nucleosome/chromatin } \\
\text { assembly factor group }\end{array}$ & 1.28 \\
\hline F6I550 (F6I550_VITVI) & CBI39729.3 & VIT_19s0015g00430.t01 & $\begin{array}{l}\text { DEK domain-containing } \\
\text { chromatin associated protein }\end{array}$ & 1.23 \\
\hline D7T5E7 (D7T5E7_VITVI) & CBI25730.3 & VIT_00s0194g00020.t01 & $\begin{array}{l}\text { DNA-directed RNA } \\
\text { polymerases IV and V subunit } \\
4 \text { isoform } X 1\end{array}$ & 1.41 \\
\hline A5BLU3 (A5BLU3_VITVI) & CBI15554.3 & VIT_17s0000g02550.t01 & Histone H1 & 1.39 \\
\hline D7TSR3 (D7TSR3_VITVI) & CBI33535.3 & VIT_14s0006g01440.t01 & $\begin{array}{l}\text { Double-stranded RNA-binding } \\
\text { protein 4-like }\end{array}$ & 1.22 \\
\hline E0CQU8 (E0CQU8_VITVI) & CBI18902.3 & VIT_18s0001g00660.t01 & High mobility group B protein 9 & 1.27 \\
\hline D7U016 (D7U016_VITVI) & CBI35962.3 & VIT_09s0002g02330.t01 & $\begin{array}{l}\text { Nucleosome assembly protein } \\
\text { 1-like isoform } 1\end{array}$ & 1.28 \\
\hline
\end{tabular}


Table 1. Cont.

\begin{tabular}{|c|c|c|c|c|}
\hline UniProtKB Accession & NCBI Accession & STRING Accession & Protein Function & $\begin{array}{l}V v M S A-\mathrm{RNAi} \\
\text { vs. WT }\end{array}$ \\
\hline D7U469 (D7U469_VITVI) & CBI37645.3 & VIT_04s0044g00110.t01 & $\begin{array}{l}\text { High mobility group B2 } \\
\text { protein-like isoform } 1\end{array}$ & 1.29 \\
\hline F6HDQ3 (F6HDQ3_VITVI) & CBI26253.3 & Not available & $\begin{array}{l}\text { Suppressor of gene silencing } \\
\text { like protein }\end{array}$ & 1.29 \\
\hline D7U7P2 (D7U7P2_VITVI) & CBI38821.3 & VIT_15s0048g01290.t01 & $\begin{array}{l}\text { Histone deacetylase complex } \\
\text { subunit SAP18 }\end{array}$ & 1.33 \\
\hline D7U4F5 (D7U4F5_VITVI) & CBI37552.3 & VIT_04s0044g01140.t01 & RNA-binding protein $8 \mathrm{~A}$ & 1.37 \\
\hline D7U5H5 (D7U5H5_VITVI) & CBI37994.3 & VIT_03s0038g00620.t01 & $\begin{array}{l}\text { Zinc finger protein GIS2-like } \\
\text { isoform } 2\end{array}$ & 0.36 \\
\hline D7T8P4 (D7T8P4_VITVI) & CBI26865.3 & VIT_01s0011g05360.t01 & HMG-Y-related protein A & 1.41 \\
\hline D7UB91 (D7UB91_VITVI) & CBI40015.3 & VIT_15s0024g00620.t01 & $\begin{array}{l}\text { Chromo domain protein } \\
\text { LHP1-like heterochromatin } \\
\text { protein } 1\end{array}$ & 1.43 \\
\hline F6GWG2 (F6GWG2_VITVI) & CBI17313.3 & VIT_05s0029g00130.t01 & $\begin{array}{l}\text { High mobility group B } \\
\text { protein 15-like }\end{array}$ & 1.44 \\
\hline D7SN59 (D7SN59_VITVI) & CBI17088.3 & VIT_06s0061g01240.t01 & Histone deacetylase HDT1-like & 1.48 \\
\hline F6HND0 (F6HND0_VITVI) & CBI31410.3 & VIT_13s0019g04940.t01 & $\begin{array}{l}\text { Protein RNA-directed DNA } \\
\text { methylation } 3 \text { isoform X1 }\end{array}$ & 1.58 \\
\hline D7UDB2 (D7UDB2_VITVI) & CBI40727.3 & VIT_18s0122g01190.t01 & $\begin{array}{l}\text { High mobility group- } \\
\text { like isoform } 1\end{array}$ & 1.75 \\
\hline F6HTB7 (F6HTB7_VITVI) & CBI33920.3 & VIT_02s0012g00870.t01 & Nucleic acid binding protein & 1.89 \\
\hline F6HIR3 (F6HIR3_VITVI) & CBI29042.3 & VIT_10s0042g00830.t01 & Lysine-specific demethylase 3B-like & 1.92 \\
\hline \multicolumn{5}{|l|}{ Metabolism $(n=13)$} \\
\hline F6GSG7 (F6GSG7_VITVI) & CBI14856.3 & VIT_17s0000g10430.t01 & $\begin{array}{l}\text { Glyceraldehyde-3-phosphate } \\
\text { dehydrogenase, cytosolic }\end{array}$ & 1.95 \\
\hline D7TGC8 (D7TGC8_VITVI) & CBI29552.3 & VIT_00s0769g00010.t01 & $\begin{array}{l}\text { Peptidyl-prolyl cis-trans } \\
\text { isomerase FKBP62 }\end{array}$ & 1.27 \\
\hline F6H4R0 (F6H4R0_VITVI) & CBI21690.3 & VIT_19s0027g01660.t01 & $\begin{array}{l}\text { Peptidyl-prolyl cis-trans } \\
\text { isomerase CYP59 isoform X1 }\end{array}$ & 1.68 \\
\hline D7U1R3 (D7U1R3_VITVI & СВI36679.3 & VIT_05s0102g00560.t01 & $\begin{array}{l}\text { Peptidyl-prolyl cis-trans } \\
\text { isomerase E }\end{array}$ & 2.04 \\
\hline F6HTX9 (F6HTX9_VITVI) & СВI34281.3 & VIT_14s0030g00950.t01 & $\begin{array}{l}\text { Superoxide dismutase } \\
\text { [Cu-Zn]-like isoform } 2\end{array}$ & 1.35 \\
\hline F6H0A2 (F6H0A2_VITVI) & CBI19970.3 & VIT_18s0001g15570.t01 & $\begin{array}{l}\text { Acetyl-CoA carboxylase } \\
\text { carboxyltransferase subunit beta }\end{array}$ & 1.21 \\
\hline D7FBB2 (D7FBB2_VITVI) & CBI25114.3 & VIT_16s0100g00580.t01 & $\begin{array}{l}\text { Nitrogen regulatory protein } \\
\text { P-II homolog }\end{array}$ & 1.23 \\
\hline D7TQA5 (D7TQA5_VITVI) & CBI32625.3 & VIT_08s0040g03150.t01 & Cytosolic ascorbate peroxidase & 1.39 \\
\hline D7SKR5 (D7SKR5_VITVI) & CBI16243.3 & VIT_06s0004g03550.t01 & L-ascorbate peroxidase 2 , cytosolic & 1.39 \\
\hline D7UDY0 (D7UDY0_VITVI) & CBI40945.3 & VIT_00s0260g00060.t01 & FK506-binding protein 2-1 & 1.41 \\
\hline D7T674 (D7T674_VITVI) & CBI25995.3 & VIT_05s0020g00600.t01 & 1-Cys peroxiredoxin & 1.47 \\
\hline F6HIE6 (F6HIE6_VITVI) & CBI28862.3 & VIT_12s0059g01320.t01 & $\begin{array}{l}\text { O-Glycosyl hydrolases family } 17 \\
\text { protein }\end{array}$ & 1.67 \\
\hline
\end{tabular}


Table 1. Cont.

\begin{tabular}{|c|c|c|c|c|}
\hline UniProtKB Accession & NCBI Accession & STRING Accession & Protein Function & $\begin{array}{c}V v M S A-\mathrm{RNAi} \\
\text { vs. WT }\end{array}$ \\
\hline D7TC92 (D7TC92_VITVI) & CBI27750.3 & VIT_11s0016g00420.t01 & Protein Red isoform 1 & 2.01 \\
\hline \multicolumn{5}{|c|}{ mRNA-splicing/Stability/Editing $(n=42)$} \\
\hline D7ST85 (D7ST85_VITVI) & CBI19999.3 & VIT_12s0055g00360.t01 & Pinin/SDK/memA protein & 1.39 \\
\hline F6HR01 (F6HR01_VITVI) & CBI32700.3 & VIT_08s0040g02300.t01 & $\begin{array}{l}\text { DEAD-box ATP-dependent } \\
\text { RNA helicase } 57\end{array}$ & 1.45 \\
\hline D7TUX6 (D7TUX6_VITVI) & CBI34301.3 & Not available & $\begin{array}{l}\text { DCD (Development and Cell } \\
\text { Death) domain protein }\end{array}$ & 1.46 \\
\hline F6GUY6 (F6GUY6_VITVI) & CBI16084.3 & VIT_06s0004g05220.t01 & $\begin{array}{l}\text { Serine/arginine repetitive } \\
\text { matrix protein }\end{array}$ & 1.50 \\
\hline D7SWX8 (D7SWX8_VITVI) & CBI21778.3 & VIT_19s0027g00590.t01 & $\begin{array}{l}\text { RNA-binding protein with serine- } \\
\text { rich domain-containing protein }\end{array}$ & 1.52 \\
\hline A5AII6 (A5AII6_VITVI) & CBI37603.3 & VIT_04s0044g00540.t01 & $\begin{array}{l}\text { Pre-mRNA-splicing factor ISY1 } \\
\text { homolog isoform } 1\end{array}$ & 1.63 \\
\hline E0CRK0 (E0CRK0_VITVI) & CBI19154.3 & VIT_18s0001g05550.t01 & $\begin{array}{l}\text { Splicing factor, } \\
\text { arginine/serine-rich }\end{array}$ & 1.68 \\
\hline F6HC22 (F6HC22_VITVI) & CBI25319.3 & VIT_13s0067g03600.t01 & $\begin{array}{l}\text { Arginine/serine-rich } \\
\text { splicing factor }\end{array}$ & 1.86 \\
\hline D7TBV2 (D7TBV2_VITVI) & CBI28137.3 & VIT_11s0016g04610.t01 & RNA-binding protein 25 & 1.74 \\
\hline D7TJ87 (D7TJ87_VITVI) & CBI30313.3 & VIT_08s0007g03130.t01 & Small nuclear ribonucleoprotein $\mathrm{G}$ & 1.74 \\
\hline F6GSZ6 (F6GSZ6_VITVI) & CBI15706.3 & VIT_17s0000g00960.t01 & $\begin{array}{l}\text { Omega-hydroxypalmitate } \\
\text { O-feruloyl transferase }\end{array}$ & 1.76 \\
\hline F6HZ42 (F6HZ42_VITVI) & CBI26627.3 & VIT_07s0005g00320.t01 & $\begin{array}{l}\text { DEAD-box ATP-dependent RNA } \\
\text { helicase } 32\end{array}$ & 1.93 \\
\hline F6GU40 (F6GU40_VITVI) & CBI16368.3 & VIT_06s0004g02220.t01 & $\begin{array}{l}\text { Heterogeneous nuclear } \\
\text { ribonucleoprotein F-like }\end{array}$ & 1.93 \\
\hline F6GUK3 (F6GUK3_VITVI) & CBI16510.3 & VIT_06s0004g00710.t01 & SC35-like splicing factor 33 & 1.21 \\
\hline A5AES3 (A5AES3_VITVI) & CBI24269.3 & VIT_06s0009g02770.t01 & $\begin{array}{l}\text { Pre-mRNA branch site } \\
\text { p14-like protein }\end{array}$ & 1.61 \\
\hline F6GXF2 (F6GXF2_VITVI) & CBI17819.3 & VIT_11s0052g01130.t01 & $\begin{array}{l}\text { CD2 antigen cytoplasmic } \\
\text { tail-binding protein }\end{array}$ & 1.31 \\
\hline F6HYI9 (F6HYI9_VITVI) & CBI36522.3 & VIT_11s0037g00130.t01 & FIP1[V]-like protein & 1.81 \\
\hline D7T5U0 (D7T5U0_VITVI) & CBI25873.3 & VIT_00s0625g00040.t01 & Polyadenylate-binding protein 2 & 1.41 \\
\hline F6HTT9 (F6HTT9_VITVI) & CBI34206.3 & VIT_14s0030g01680.t01 & $\begin{array}{l}\text { MKI67 FHA domain-interacting } \\
\text { nucleolar phosphoprotein }\end{array}$ & 1.27 \\
\hline D7TU07 (D7TU07_VITVI) & CBI33922.3 & VIT_02s0012g00850.t01 & $\begin{array}{l}\text { Pre-mRNA-splicing factor } \\
\text { CWC26 }\end{array}$ & 1.29 \\
\hline F6HYH6 (F6HYH6_VITVI) & CBI36502.3 & VIT_04s0159g00020.t01 & Polyadenylate-binding protein & 1.28 \\
\hline D7TLV0 (D7TLV0_VITVI) & CBI31687.3 & VIT_13s0019g01060.t01 & $\begin{array}{l}\text { Serine/arginine rich } \\
\text { splicing factor }\end{array}$ & 1.32 \\
\hline D7SJN7 (D7SJN7_VITVI) & CBI15863.3 & VIT_06s0004g07530.t01 & Spliceosomal protein & 1.35 \\
\hline F6H257 (F6H257_VITVI) & CBI20322.3 & VIT_19s0014g02920.t01 & $\begin{array}{l}\text { Pentatricopeptide } \\
\text { repeat-containing protein }\end{array}$ & 1.28 \\
\hline D7T3P2 (D7T3P2_VITVI) & CBI25124.3 & VIT_03s0088g00390.t01 & $\begin{array}{l}\text { DnaJ homolog subfamily C } \\
\text { member 17-like }\end{array}$ & 1.25 \\
\hline
\end{tabular}


Table 1. Cont.

\begin{tabular}{|c|c|c|c|c|}
\hline UniProtKB Accession & NCBI Accession & STRING Accession & Protein Function & $\begin{array}{l}V v M S A \text {-RNAi } \\
\text { vs. WT }\end{array}$ \\
\hline F6GWL6 (F6GWL6_VITVI) & CBI17355.3 & VIT_04s0023g03630.t01 & $\begin{array}{l}\text { Pre-mRNA-splicing } \\
\text { factor CWC25 }\end{array}$ & 1.29 \\
\hline F6H2X4 (F6H2X4_VITVI) & CBI20826.3 & VIT_04s0008g03130.t01 & $\begin{array}{l}\text { Pre-mRNA-splicing } \\
\text { factor CWC21-like }\end{array}$ & 1.30 \\
\hline D7TT33 (D7TT33_VITVI) & CBI33655.3 & VIT_14s0006g02960.t01 & Poly C-binding protein & 0.36 \\
\hline F6I0Z0 (F6I0Z0_VITVI) & CBI37849.3 & VIT_03s0038g02620.t01 & Splicing factor & 1.39 \\
\hline F6GYT6 (F6GYT6_VITVI) & CBI18525.3 & VIT_18s0117g00150.t01 & $\begin{array}{l}\text { Heterogeneous nuclear } \\
\text { ribonucleoprotein } 27 \mathrm{C}\end{array}$ & 1.44 \\
\hline F6HP66 (F6HP66_VITVI) & CBI31839.3 & VIT_16s0100g00450.t01 & $\begin{array}{l}\text { Arginine/serine-rich-splicing } \\
\text { factor RSP40 }\end{array}$ & 1.44 \\
\hline D7UAL8 (D7UAL8_VITVI) & CBI39783.3 & VIT_19s0015g00980.t01 & Pre-mRNA-splicing factor cwc15 & 1.45 \\
\hline D7TAD5 (D7TAD5_VITVI) & CBI27458.3 & VIT_01s0010g01410.t01 & RNA-binding protein-like & 1.53 \\
\hline F6I0P5 (F6I0P5_VITVI) & CBI37715.3 & VIT_03s0038g04130.t01 & $\begin{array}{l}\text { DEAD-box ATP-dependent RNA } \\
\text { helicase 42-like }\end{array}$ & 1.56 \\
\hline F6H177 (F6H177_VITVI) & CBI19367.3 & VIT_18s0001g08680.t01 & $\begin{array}{l}\text { Pre-mRNA-processing } \\
\text { protein } 40 \mathrm{~B}\end{array}$ & 1.62 \\
\hline F6GTQ4 (F6GTQ4_VITVI) & CBI14910.3 & VIT_17s0000g09680.t01 & $31 \mathrm{kDa}$ ribonucleoprotein & 1.67 \\
\hline F6GWX4 (F6GWX4_VITVI) & CBI17535.3 & VIT_04s0023g01580.t01 & $\begin{array}{l}\mathrm{U} 1 \text { small nuclear } \\
\text { ribonucleoprotein } 70 \mathrm{kDa}\end{array}$ & 1.70 \\
\hline F6HI04 (F6HI04_VITVI) & CBI28632.3 & VIT_04s0043g00270.t01 & Pre-mRNA-splicing factor 38B & 1.72 \\
\hline F6I0K0 (F6I0K0_VITVI) & CBI37648.3 & VIT_04s0044g00080.t01 & $\begin{array}{l}\text { Heterogeneous nuclear } \\
\text { ribonucleoprotein F }\end{array}$ & 1.78 \\
\hline D7UD56 (D7UD56_VITVI) & CBI40671.3 & VIT_11s0078g00440.t01 & $\begin{array}{l}\text { U4/U6.U5 tri-snRNP- } \\
\text { associated protein }\end{array}$ & 1.82 \\
\hline F6HF25 (F6HF25_VITVI) & CBI27081.3 & VIT_01s0011g02820.t01 & Protein decapping 5 isoform $X 1$ & 1.85 \\
\hline F6HTK3 (F6HTK3_VITVI) & CBI34075.3 & VIT_03s0017g01340.t01 & $\begin{array}{l}\text { Heterogeneous nuclear } \\
\text { ribonucleoprotein } Q\end{array}$ & 2.10 \\
\hline \multicolumn{5}{|c|}{ rRNA processing/Biogenesis $(n=13)$} \\
\hline D7T103 (D7T103_VITVI) & CBI24130.3 & VIT_19s0085g01090.t01 & Nuclear-pore anchor-like & 1.29 \\
\hline E0CQ61 (E0CQ61_VITVI) & CBI19866.3 & VIT_18s0001g14320.t01 & Nucleolar protein 58 isoform $\mathrm{X} 1$ & 1.52 \\
\hline F6GST5 (F6GST5_VITVI) & CBI15641.3 & VIT_17s0000g01640.t01 & $\begin{array}{l}\text { RNA-metabolising } \\
\text { metallo-beta-lactamase } \\
\text { family protein }\end{array}$ & 1.93 \\
\hline F6H683 (F6H683_VITVI) & CBI22501.3 & VIT_03s0091g00320.t01 & $\begin{array}{l}\text { Ribosomal RNA assembly } \\
\text { protein mis3-like }\end{array}$ & 0.72 \\
\hline F6HLD3 (F6HLD3_VITVI) & СВI30568.3 & VIT_08s0007g00190.t01 & $\begin{array}{l}\text { H/ACA ribonucleoprotein } \\
\text { complex subunit } 4\end{array}$ & 1.45 \\
\hline D7T1S3 (D7T1S3_VITVI) & CBI24453.3 & VIT_00s0264g00120.t01 & Scaffold attachment factor B1 & 1.91 \\
\hline C5DB53 (C5DB53_VITVI) & CBI31135.3 & VIT_08s0056g00160.t01 & $\begin{array}{l}\text { U3 small nucleolar } \\
\text { RNA-associated protein } 11\end{array}$ & 1.34 \\
\hline F6GZQ7 (F6GZQ7_VITVI) & CBI16359.3 & VIT_18s0001g13560.t01 & Midasin & 1.21 \\
\hline F6HF03 (F6HF03_VITVI) & CBI27323.3 & VIT_01s0011g00070.t01 & Nucleolar protein 14-like & 1.50 \\
\hline D7STQ8 (D7STQ8_VITVI) & CBI20657.3 & VIT_04s0008g01200.t01 & $\begin{array}{l}\text { Translation machinery-associated } \\
\text { protein } 22 \text { isoform } 2\end{array}$ & 0.33 \\
\hline
\end{tabular}


Table 1. Cont.

\begin{tabular}{|c|c|c|c|c|}
\hline UniProtKB Accession & NCBI Accession & STRING Accession & Protein Function & $\begin{array}{l}V v M S A \text {-RNAi } \\
\text { vs. WT }\end{array}$ \\
\hline F6I6B2 (F6I6B2_VITVI) & CBI40495.3 & VIT_15s0046g01120.t01 & $\begin{array}{l}\text { Ribosome biogenesis regulatory } \\
\text { protein homolog }\end{array}$ & 1.58 \\
\hline D7U276 (D7U276_VITVI) & CBI36842.3 & VIT_07s0005g00270.t01 & $\begin{array}{l}\text { Nucleolar protein } 16 \text { involved in } \\
\text { ribosome biogenesis }\end{array}$ & 1.90 \\
\hline F6GXL7 (F6GXL7_VITVI) & CBI17936.3 & VIT_07s0141g00380.t01 & $\begin{array}{l}\text { U3 small nucleolar RNA- } \\
\text { associated protein-like protein }\end{array}$ & 2.00 \\
\hline \multicolumn{5}{|l|}{ Stress responses $(n=13)$} \\
\hline F6HS56 (F6HS56_VITVI) & CBI33350.3 & VIT_05s0051g00650.t01 & $\begin{array}{l}\text { Voltage-gated potassium } \\
\text { channel subunit beta }\end{array}$ & 0.72 \\
\hline E0CUG6 (E0CUG6_VITVI) & CBI22747.3 & VIT_16s0050g00140.t01 & Metal ion binding protein & 1.63 \\
\hline F6GY60 (F6GY60_VITVI) & CBI18236.3 & VIT_18s0072g00160.t01 & Peroxidase 12-like & 1.34 \\
\hline D7TUZ6 (D7TUZ6_VITVI) & CBI34321.3 & VIT_14s0030g00430.t01 & $\begin{array}{l}\text { Prefoldin chaperone subunit } \\
\text { family protein }\end{array}$ & 1.21 \\
\hline E0CRL1 (E0CRL1_VITVI) & CBI19165.3 & VIT_18s0001g05720.t01 & 14-3-3 protein 7 & 1.27 \\
\hline F6H0X3 (F6H0X3_VITVI) & CBI19195.3 & VIT_18s0001g06330.t01 & 14-3-3 protein & 1.49 \\
\hline F6H824 (F6H824_VITVI) & CBI23432.3 & VIT_00s0250g00040.t01 & DNA-binding protein & 1.21 \\
\hline D7SU28 (D7SU28_VITVI) & CBI20777.3 & VIT_04s0008g02590.t01 & Selenium binding protein & 1.22 \\
\hline F6HEA6 (F6HEA6_VITVI) & CBI26439.3 & VIT_16s0039g01020.t01 & $\begin{array}{l}\text { Adenylate cyclase, } \\
\text { terminal-differentiation specific }\end{array}$ & 1.30 \\
\hline D7TIR0 (D7TIR0_VITVI) & CBI30136.3 & Not available & $\begin{array}{l}\text { Arginine/serine-rich coiled-coil } \\
\text { protein } 2 \text { isoform X2 }\end{array}$ & 1.43 \\
\hline F6H1I0 (F6H1I0_VITVI) & CBI19683.3 & VIT_18s0001g12350.t01 & $\begin{array}{l}\text { Protein ESSENTIAL FOR } \\
\text { POTEXVIRUS } \\
\text { ACCUMULATION X1 }\end{array}$ & 1.59 \\
\hline F6H2Z1 (F6H2Z1_VITVI) & CBI20901.3 & Not available & $\begin{array}{l}\text { Dehydration-responsive } \\
\text { protein RD22 }\end{array}$ & 1.93 \\
\hline F6HE42 (F6HE42_VITVI) & CBI26016.3 & VIT_05s0020g00840.t01 & $\begin{array}{l}\text { Late embryogenesis abundant } \\
\text { protein D-29 }\end{array}$ & 4.17 \\
\hline \multicolumn{5}{|c|}{ Transcriptional regulation $(n=20)$} \\
\hline F6H7R2 (F6H7R2_VITVI) & CBI23284.3 & VIT_07s0197g00070.t01 & $\begin{array}{l}\text { Upstream activation factor } \\
\text { subunit spp27-like }\end{array}$ & 1.59 \\
\hline D7SIK8 (D7SIK8_VITVI) & CBI15319.3 & VIT_17s0000g05190.t01 & $\begin{array}{l}\text { Zinc finger } \mathrm{CCCH} \\
\text { domain-containing protein }\end{array}$ & 1.64 \\
\hline D7TCU3 (D7TCU3_VITVI) & CBI28316.3 & VIT_06s0080g00460.t01 & $\begin{array}{l}\text { Nuclear transcription factor } Y \\
\text { subunit B-8 }\end{array}$ & 1.71 \\
\hline D7TDY1 (D7TDY1_VITVI) & CBI28704.3 & VIT_07s0151g00910.t01 & NF-kappa-B-activating protein & 1.21 \\
\hline F6HSW0 (F6HSW0_VITVI) & CBI33736.3 & VIT_07s0129g00610.t01 & FRIGIDA-like isoform 2 & 1.28 \\
\hline F6I111 (F6I111_VITVI) & CBI37898.3 & VIT_03s0038g02130.t01 & $\begin{array}{l}\text { Cold-shock DNA } \\
\text { binding protein }\end{array}$ & 1.47 \\
\hline D7UDF0 (D7UDF0_VITVI) & CBI40765.3 & Not available & AT-hook protein 1 & 1.36 \\
\hline D7SK51 (D7SK51_VITVI) & CBI16027.3 & VIT_06s0004g05830.t01 & $\begin{array}{l}\text { DNA-directed RNA } \\
\text { polymerases I and III subunit } \\
\text { RPAC2 isoform } 1\end{array}$ & 1.25 \\
\hline F6HZB5 (F6HZB5_VITVI) & CBI36973.3 & VIT_07s0005g01740.t01 & $\begin{array}{l}\text { Zinc knuckle (CCHC-type) } \\
\text { family protein }\end{array}$ & 1.37 \\
\hline
\end{tabular}


Table 1. Cont.

\begin{tabular}{|c|c|c|c|c|}
\hline UniProtKB Accession & NCBI Accession & STRING Accession & Protein Function & $\begin{array}{c}V v M S A \text {-RNAi } \\
\text { vs. WT }\end{array}$ \\
\hline F6HIW1 (F6HIW1_VITVI) & CBI29150.3 & VIT_13s0047g00310.t01 & $\begin{array}{l}\text { Serrate RNA effector } \\
\text { molecule-like }\end{array}$ & 1.37 \\
\hline E0CNQ9 (E0CNQ9_VITVI) & CBI19287.3 & VIT_18s0001g07750.t01 & Neuroguidin-like & 1.38 \\
\hline F6HAX1 (F6HAX1_VITVI) & CBI24668.3 & VIT_05s0094g00440.t01 & $\begin{array}{l}\text { Sas10/U3 ribonucleoprotein } \\
\text { family protein }\end{array}$ & 1.42 \\
\hline D7SII5 (D7SII5_VITVI) & CBI15296.3 & VIT_17s0000g05450.t01 & Early flowering 5 protein & 1.43 \\
\hline D7TZU6 (D7TZU6_VITVI) & CBI35892.3 & VIT_09s0002g01530.t01 & $\begin{array}{l}\text { GBF-interacting protein 1-like } \\
\text { isoform X1 }\end{array}$ & 1.52 \\
\hline F6HH48 (F6HH48_VITVI) & CBI28116.3 & VIT_11s0016g04390.t01 & Nucleolar protein dao-5-like & 1.54 \\
\hline F6HFZ8 (F6HFZ8_VITVI) & CBI27460.3 & VIT_01s0010g01440.t01 & $\begin{array}{l}\text { Transcription elongation } \\
\text { regulator 1-like }\end{array}$ & 1.57 \\
\hline D7TTQ2 (D7TTQ2_VITVI) & CBI33817.3 & VIT_02s0012g02250.t01 & Transcription factor HBP-1a & 1.69 \\
\hline F6I758 (F6I758_VITVI) & CBI40894.3 & VIT_13s0175g00120.t01 & $\begin{array}{l}\text { ABSCISIC ACID-INSENSITIVE } \\
\text { 5-like protein 2-like isoform } 1\end{array}$ & 1.75 \\
\hline F6HLJ6 (F6HLJ6_VITVI) & CBI30026.3 & VIT_08s0007g06400.t01 & $\begin{array}{l}\text { Zinc finger } \mathrm{CCCH} \\
\text { domain-containing protein } \\
\text { 14-like isoform } 1\end{array}$ & 1.83 \\
\hline D7SIC5 (D7SIC5_VITVI) & CBI15235.3 & VIT_17s0000g06060.t01 & Activating signal cointegrator 1 & 2.00 \\
\hline
\end{tabular}

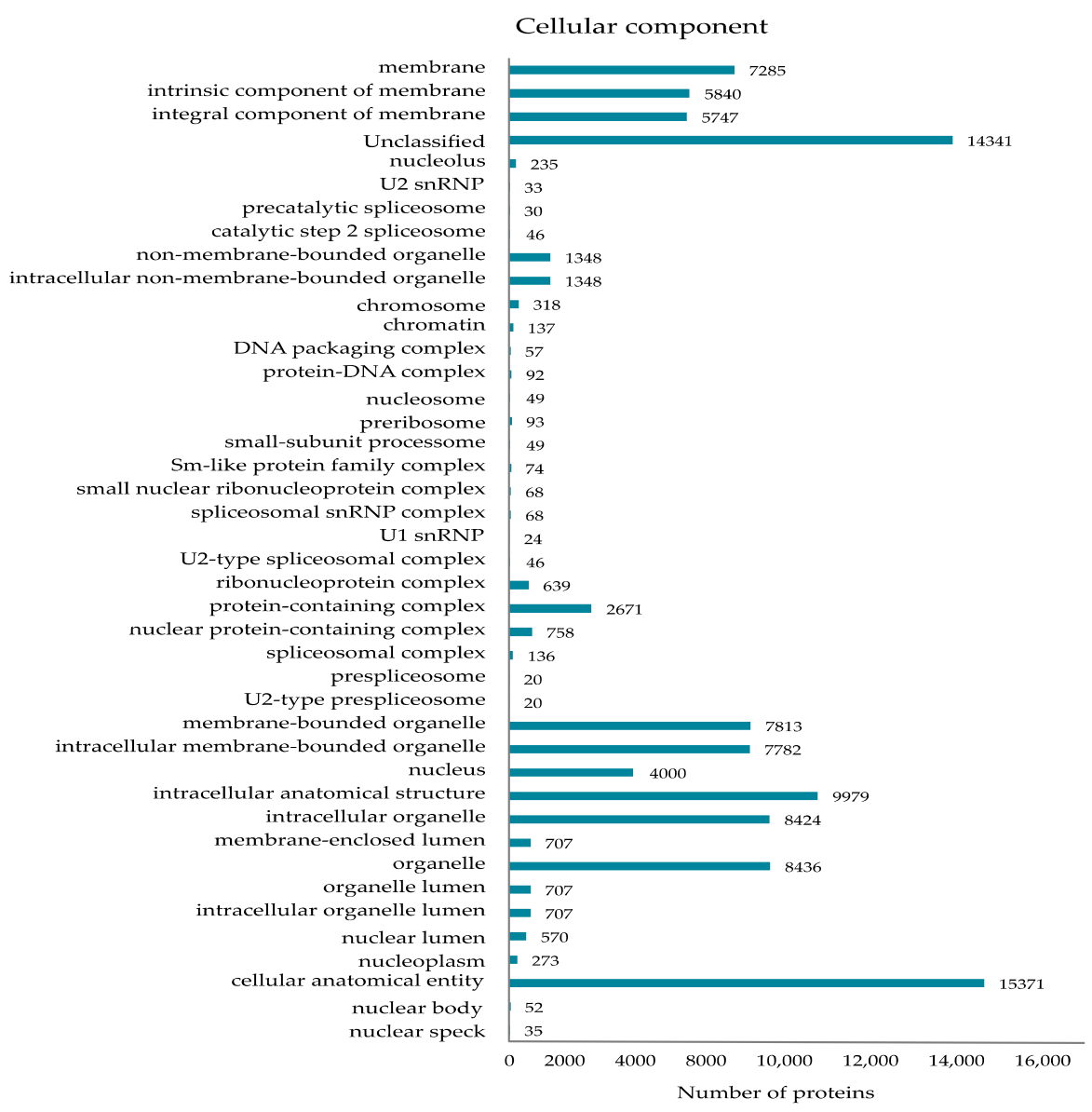

Figure 2. GO classification of the DEPs by localization as cellular components. 


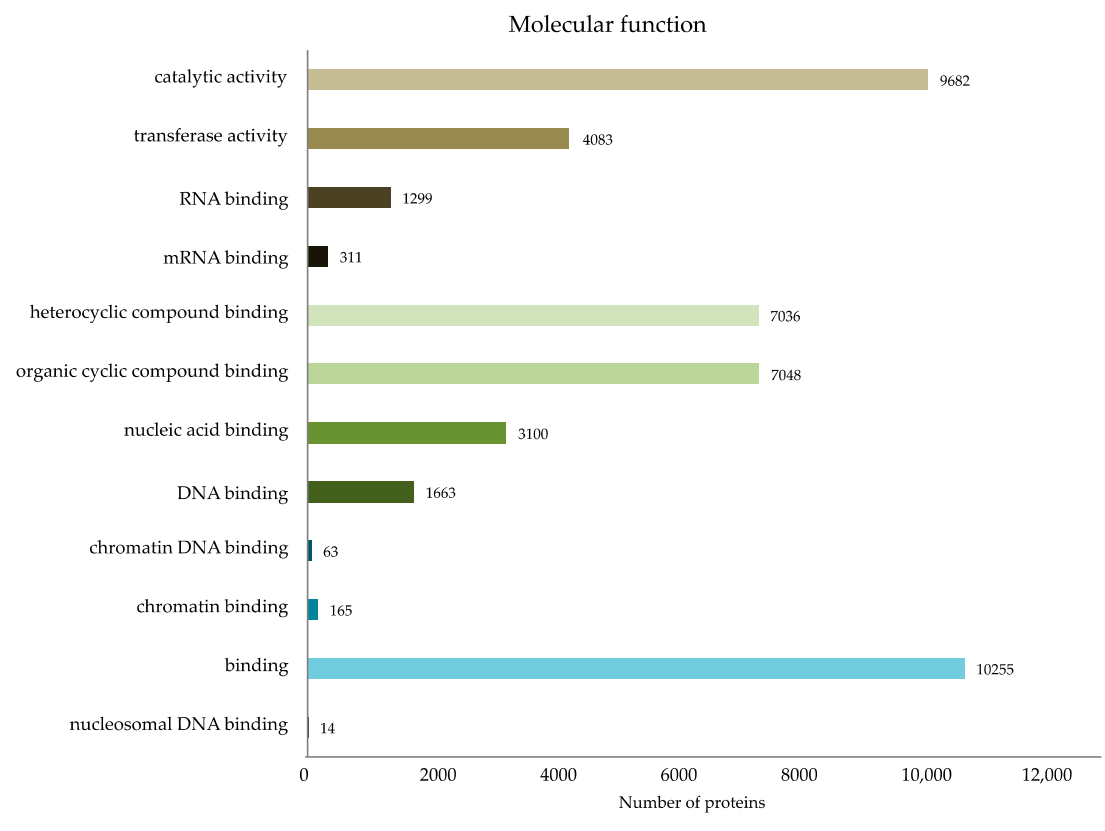

Figure 3. GO classification of the DEPs by molecular functions.

\subsection{Late Embryogenesis Abundant Protein VvLEA-D29}

Our proteomic analysis revealed VvLEA D-29 as the most affected protein by the VvMSA silencing, which displayed a $\log 2$ fold change of 4.17 responding to nearly 18 -fold up-regulation in $V v M S A$-RNAi-A cells compared to that of the wild-type cells (Figure 4A). This was further confirmed by the significant overexpression of $V v L E A D-29$ gene in the same transgenic $V v M S A$-RNAi-A cells, as demonstrated by real-time qPCR (Figure 4A). Despite the strong increase at both protein and gene levels, the protein displayed a higher induction when compared to that of the gene, which highlights the importance of posttranscriptional regulation in the accumulation of LEA protein in grape VvMSA-RNAi cells. Because of the embryogenic nature of the grape $41 \mathrm{~B}$ cells, VvMSA and VvLEA $D-29$ expression was further analyzed under conditions of initial triggering of somatic embryogenesis by auxin depletion of the culture medium. Both genes demonstrated strong and contrasted responsiveness to auxin depletion, nearly 18-fold down-regulation of $V v M S A$ and more than 7-fold up-regulation of $V v L E A D-29$ (Figure 4B). Eventually, in silico STRING analysis for protein-protein interaction and functional enrichment provided additional argument in favor of the plausible relationship between VvMSA and VvLEA D-29 (Figure 4C).

As most members of the LEA superfamily are either partially or entirely IDPs [39,40], we checked the presence of short clusters enriched in hydrophobic amino acids corresponding to Molecular Recognition Elements (MOREs) in the sequence of VvLEA D-29 by MoRFpred prediction. Grape LEA D-29 encompasses several disordered regions in its amino acid sequence, and consequently, it may also be considered as partially disordered (Figure 5A). Furthermore, we looked for structural disorders in the primary sequence of grape ASR. The in silico analysis of disordered regions of grape ASR and their comparison with four characterized ASR proteins from tomato, banana, barley and wheat [23-25] brought evidence for the presence of five almost identical regions of disorder within the VvMSA sequence (Figure 5B). The zinc-induced gain of structure also results in a conformational transition and, consequentially, in decreased susceptibility to trypsin digestion, as already reported for tomato ASR1 $[23,41]$. The $\mathrm{Zn}^{2+}$-biding region (PEHAHKHK), previously identified in tomato ASR, is also conserved in the other ASR proteins that are characterized as IDPs (Figure 5B). 
A .

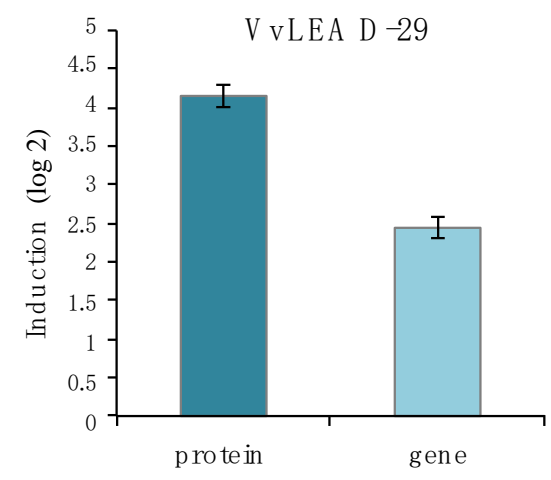

B.

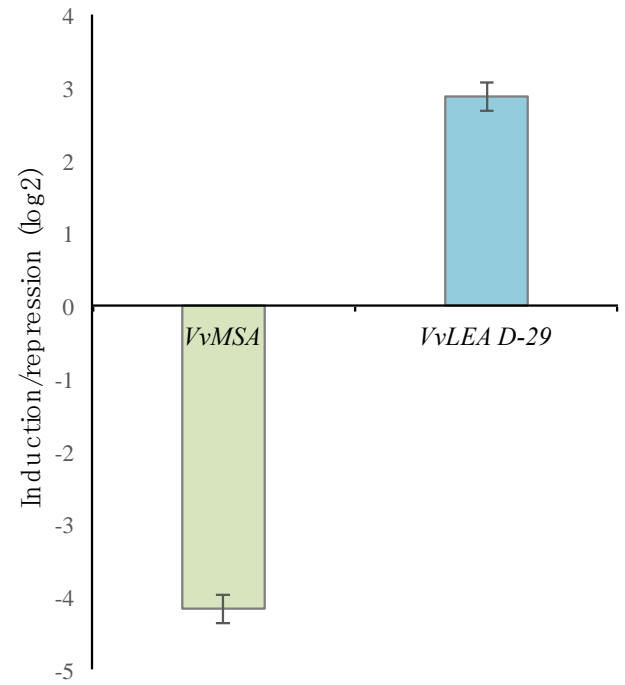

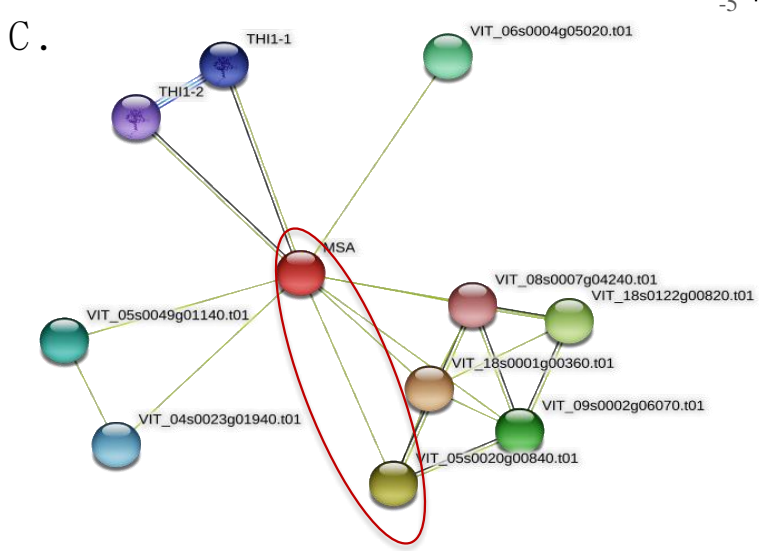

Figure 4. Relationship between VvMSA and VvLEA D-29 genes and proteins. (A) Induction of LEA D-29 protein in VvMSA-RNAi silenced cells (quantified by iTRAQ) and LEA D-29 gene expression in $V v M S A$-RNAi cells (measured by RT-qPCR). The expression of $L E A D-29$ gene in $V v M S A-R N A i$ cells was reported to that of the control wild-type cells (previously normalized to the reference $V v A C T$ gene) and the induction of $L E A D-29$ (presented on the figure) was then calculated by the $2^{-\Delta \Delta \mathrm{Ct}}$ method, as $\log 2$ fold change (mean $\pm \mathrm{SE}$ ). (B) Down-regulation of $V v M S A$ and up-regulation of $V v L E A D-29$ genes by auxin depletion at the 4th day after somatic embryogenesis induction of wild-type 41B cells (three biological repetitions). The expression of each gene under auxin depletion (previously normalized to the reference $V v A C T$ gene) was reported to that of $41 \mathrm{~B}$ cells cultured into auxin-supplemented medium by using the $2^{-\Delta \Delta \mathrm{Ct}}$ method (mean $\pm \mathrm{SE}$ ). (C) Relationship between grape ASR (MSA; VIT_18s0072g00380.t01) and Late Embryogenesis Abundant protein LEA D-29 (VIT_05s0020g00840.t01) established by using the protein-protein interaction and functional enrichment network STRING (https:/ / string-db.org/; accessed on 1 May 2021) in Vitis vinifera.

\subsection{Impact of VvMSA Repression on H3 and H4 Histone Post-Translational Modifications (HPTMs)}

We have previously characterized the grape ASR as a transcription factor of the architectural type belonging to the chromatin fraction of nuclear proteins [32]. In parallel, twenty-nine proteins involved with epigenetic regulation displayed quantitative differences (Table 1), which implies shifts of post-translational modifications of the histones $\mathrm{H} 3$ and H4. The latter raises the pertinent question of whether $V v M S A$ silencing affects histone marks. To that aim, we compared HPTM changes between the three generated independent $V v M S A-R N A i$ transgenic cell lines (biological replicates) and the original wild-type cell line, each of them tested in three technical replicates. We developed a custom mediumthroughput immunoblot assay of multiplex type coupled with ImageQuant TL analysis to simultaneously test immunodetection histone H3 and H4 PTMs versus a panel of twenty 
antibodies, using ECL. The used monoclonal primary antibodies were directed against eighteen HPTMs of lysine residues: twelve of histone $\mathrm{H} 3$ (nine methylations and three acetylations) and six of histone $\mathrm{H} 4$ (five acetylations and one methylation) (Figure 6A; Table S1). All data of quantified HPTMs were normalized to those of their respective histone by using monoclonal antibodies raised to synthetic peptide $\mathrm{H} 3$ and $\mathrm{H} 4$ whole sequences devoid of any HPTM.

A

VvLEA D-29

MASFSSRKPCESSSRRVMALVLVVMVVVVLTRGCSCSHVTEEVKGQVKAQEKAAEAEEEAKE ASESWAEWAKDKISQNLRLKQEKQASDSATETAKSQDTAEEAASGAGQYAEKADEAKKVLKE KTEETKGAASQKACEAKAAEAKETASQKVGEAKEKAGGVTEKAAEAKEKVAEKAREVKEKAA QKAEEAKEKAYHKTEEAKEAAKEKGAKAEESVSWAKEKAKESFDAGKAKAGETLEKAKERIE AAKENIGGRGGDEEL

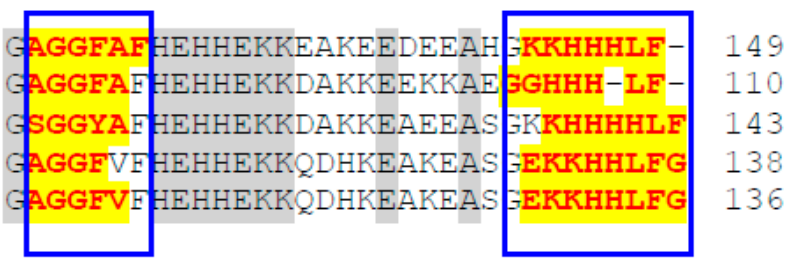

Figure 5. Prediction of the intrinsically disordered regions by MoRFpred. (A) Identification of Molecular Recognition Elements (MOREs) in the sequence of VvLEA D-29. (B) Multiple sequence alignment of five ASRs with their predicted intrinsically disordered regions: VvMSA (Vitis vinifera); SlASR (Solanum lycopersicum); MpASR (Musa ABB Group); HvASR1 (Hordeum vulgare); TtASR1 (Triticum turgidum subsp. Durum). The amino acids in bold, red, and highlighted in yellow denote the short disorder-to-order transitioning binding regions (blue frame). The amino acids in normal, black and highlighted in gray are identical in all of the five ASR sequences. The $\mathrm{Zn}^{2+}$-binding region PEHAHKHK (red frame) is identical in grape, tomato, plantain, barley and wheat.

In regard of histone $\mathrm{H} 3$ we detected statistically significant differences between the VvMSA-RNAi cells and the wild-type cells in six out of the eleven detected HPTMs: H3K4me1, H3K4me3, H3K9me1, H3K9me2, H3K36me2 and H3K36me3. No statistical difference was observed for H3K4me2, H3K9ac, H3K14ac, H3K27me1 and H3K27me3. One histone H3 PTM (H3K27ac) was not detected (Figure 6B). Concerning the histone H4, only two out of the six tested HPTMs were detected (i.e., H4K16ac and H4K20ac), while three other HPTMs were undetectable (H4K5ac, H4K12ac, H4K20me1) and the used antibody to H4K8ac produced multiple artefactual bands. Most importantly, H4K16ac was detected only in the wild-type 41B cells, which underlies its depletion in the three independently transformed VvMSA-RNAi cell lines (Figure 6B). The other marked changes in the VvMSA-RNAi cells consisted of a nearly two-fold increase in H3K9me2, two-fold 
decrease in $\mathrm{H} 3 \mathrm{~K} 9 \mathrm{me} 1$ and five-fold decrease in $\mathrm{H} 3 \mathrm{~K} 36 \mathrm{me} 2$ (Figure S5). The latter results were visualized on a heat map (Figure 6C, Table S3).

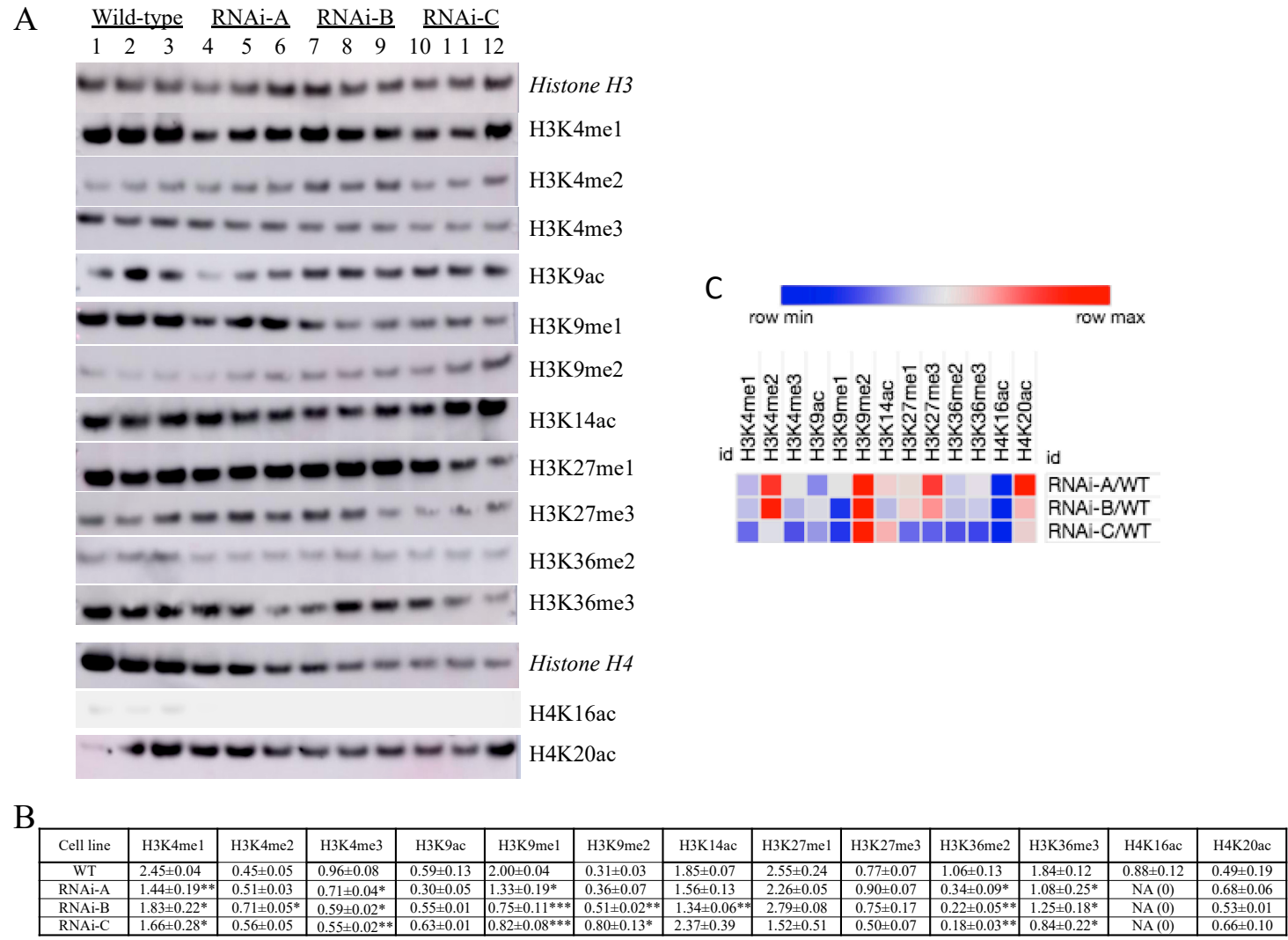

Figure 6. Immunoblot analysis of histone H3 and H4 PTMs at the level of the total chromatin of wild-type and three independent VvMSA-RNAi transgenic lines (biological replicates) of grape embryogenic cells 41B. (A) Histone PTMs' immunodetection of the four cell lines, each tested in three technical replicates. The loading controls stained with Ponceau S are presented in Figure S5. (B) The quantified HPTM data were first normalized to those of their respective native histone (H3 or $\mathrm{H} 4)$. The values of the three technical replicates for each of the four tested cell lines were presented as mean \pm SEM. The asterisks denote the level of significant difference between the wild-type and each of the RNAi cell lines evaluated by unpaired $t$ test: ${ }^{*} p<0.05 ;{ }^{* *} p<0.01$; ${ }^{* * *} p<0.001$. In the column of H4K16ac statistics was not applicable (NA) because of undetectable signal in the three tested RNAi cell lines. (C) Heat map of the mean VvMSA-RNAi/WT ratios of the three biological replicates (Morpheus, https:/ / software.broadinstitute.org/morpheus; accessed on 1 May 2021). The heat map was built using the mean VvMSA-RNAi/WT values presented in Table S3.

\section{Discussion}

ASR proteins, at the example of VvMSA, are expressed in the transitions between different stages of plant development and in plant responses to environmental cues, mediated by complex interplay of endogenous (hormonal and metabolic) and exogenous signals [21]. Each of these respective developmental transitions and adaptive responses is subject to strong metabolic changes, transduced by specific epigenetic modifications and consequent differential expression of distinct sets of genes (recently reviewed by Leung and Gaudin, 2020) [42]. In plants, the genes encoding transcription factors are favorite targets of epigenetic regulations, and are considered to represent nearly $15 \%$ of all protein coding genes. In addition, their combinatory effects on gene expression are further fine-tuned by the mechanisms of post-transcriptional control. Studies on plant processome/ribosome proteins provide evidence for their essential role in regulation of plant development [43-45] and response to environmental stresses [46-48]. Another level of complexity of plant ribosomal proteins is dealing with the existence of several 
paralogues displaying divergent functions due to their post-translational modifications (acetylation and phosphorylation). Such additional functionalization appears dependent on genetic or epigenetic factors and provides sub-specialization of the different ribosomal proteins allowing adaptation of the plant response to environmental factors [48]. In this general context, the silencing of the only one ASR found in grape impacts nuclear proteome by up- or down-regulation of 146 proteins clustered in the functional groups of metabolism, epigenetic regulation, DNA replication and repair, transcriptional regulation mRNA-splicing, stability and editing, rRNA processing and biogenesis, cell division and differentiation, and stress response (Table 1).

In our study the generated VvMSA-RNAi silenced cells and their control, the WT cell line, were chosen as an appropriate model because of the lack of apparent differences in terms of cell morphology, proliferation rate and differentiation potential. It is worth noting that the glucose absorption by VvMSA-RNAi silenced cells decreased nearly two-fold in comparison to the WT cells (our unpublished results). The latter corroborates the idea that the repression of grape ASR affects plant metabolism, and this in the absence of apparent phenotypic alterations (Figure $1 B, C$ ). In this regard, we have already reported that $41 \mathrm{~B}$ embryogenic cells cope with the low level of intracellular glucose and the low glycolysis efficiency still capable of sustaining their organized cell proliferation [49]. Furthermore, genetically modified plantlets, regenerated from transgenic somatic embryos, did not display apparent phenotypic differences when compared to those of the wild-type plantlets cultured under the same heterotrophic conditions (Figure S1). Although these transgenic grape plantlets may be "indefinitely" micro-propagated under heterotrophic conditions, they were not able to acclimate to autotrophic conditions. The failure of acclimation of grape ASR-silenced plantlets from heterotrophic to autotrophic conditions represented the most marked phenotypic difference when compared to in vitro regenerated WT plantlets. Such an issue may be explained by the roles of ASRs in transcriptional regulation of some sugar transporter genes, glucose metabolism and glucose signaling [11,16,18]. In the latter regard, Dominguez and co-authors have already demonstrated the crucial impact of antisense reduced expression of tomato ASR1 on the decrease in $\mathrm{CO}_{2}$ assimilation and sucrose loading in phloem, concomitant with the increase of glucose accumulation in leaf mesophyll cells, at the crosstalk between sugar, ABA and gibberellin signaling pathways. They have also provided evidence for partial degradation of large and small Rubisco subunits, as well as for induced production of oxygen reactive species as marks of accelerated developmental senescence due to glucose accumulation in leaves and related glucose signal transduction via its cytosolic sensor the HXK1 [19].

One of our conspicuous findings concerns the fact that after VvMSA repression the majority of DEPs turn up-regulated, which emphasizes the critical functions of the ASRs in plant developmental transitions and stress responses. Interestingly, the most up-regulated protein in our study, VvLEA D-29, belongs to the superfamily of the late embryogenesis abundant proteins (LEAPs). These highly hydrophilic proteins are considered to play a crucial role in plant adaptive response, at the onset of abiotic stresses induced by low temperatures (cold and freezing), dehydration, and salinity [22,50]. The LEAPs have initially been discovered to accumulate in the last phases of embryo development, as protection against protein aggregation under seed desiccation. In the latter context, it should be pointed out that our present results were obtained on grape embryogenic 41B cells, mainly used for genetic transformation through differentiation of transgenic somatic embryos.

The grape LEA D-29 (VvLEA D-29) protein displaying LEA4 domain has been identified in grapevine as the unique member of subclass 4 of the large LEA family [51]. The nucleo-cytosolic localization of VvLEA D-29 has been demonstrated, and its encoding gene has been characterized in two different grape cultivars as up-regulated by salinity and PEG-induced osmotic stress [51]. The strongly induced expression of VvLEA D-29 under grape ASR repression, the abiotic stresses responsiveness and the nuclear localization of these two proteins, argue in favor of a possible compensatory effect of VvLEA D-29 
to VvMSA silencing. It is worth mentioning that the specific silencing of rice ASR5 by microRNA approach has been compensated by concomitant induction of rice ASR1 [15]. In addition, it has been demonstrated that the functional complementarity of both of these OsASR proteins erases the dwarf phenotype due to the simultaneous RNAi silencing of OsASR1 and OsASR5, and OsASR1 expression perfectly restores the normal phenotype under OsASR5 depletion [8,15]. Even though grape ASR and grape LEA 29-D belong to two different groups of LEAPs, our results suggest a plausible compensatory effect between them under $V v M S A$-silencing and auxin depletion.

Aberrant electrophoretic migration as another characteristic trait of protein disorder has already been demonstrated for VvMSA (theoretical MW of $16.5 \mathrm{kDa}$ ), whose MW after denaturing electrophoresis is estimated at 23.4 and $24 \mathrm{kDa}$ for the deleted and the complete forms, respectively [11,32]. The extremely high sequence homology of disorder responsible regions, shared by the grape ASR and the four above-mentioned ASR proteins, as well as its aberrant electrophoretic mobility, allowed us to predict VvMSA as a potential IDP. The IDPs have been described as highly dynamic and conformational heterogeneous structures showing a propensity to undergo induced partial folding upon binding to a partner or under constraint non-physiological conditions [52-54]. The disordered nature of the four above-mentioned ASRs highlights structural similarities between ASR and LEA, and corroborates the classification of ASR proteins as a subfamily of the LEAPs superfamily $[22,49,55,56]$. A hypothesis, whose veracity has yet to be tested, predicts many LEAPs as positively associated with stress memory in Arabidopsis [57].

As the functional base of stress memory relies on different epigenetic modifications, we further explored HPTMs at total chromatin level. At the current state of knowledge, the challenge consists of deciphering the causal relationship between changes in HPTMs and those at transcription level. The transcriptional machinery is strongly dependent on local high-ordered structures of chromatin, which determines its accessibility and represents a biologically active platform for complex nucleic acids and proteins interactions. In other terms, the chromatin structural context tightly impacts the effectiveness of transcriptional regulation, and thereby its remodeling controls gene expression. The genome-wide analysis of histone marks and their plotting to transcription activity have revealed $\mathrm{H} 3 \mathrm{~K} 4 \mathrm{me} 3$ and $\mathrm{H} 3 \mathrm{~K} 36 \mathrm{me} 3$ post-translational modifications as positive marks of actively transcribed genes, and $\mathrm{H} 3 \mathrm{~K} 27 \mathrm{me} 3$ as a negative mark of transcriptionally inactive genes [58-61]. Consequentially, these HPTMs have been related to two different chromatin states (CS): CS1 enriched with H3K4me3 and H3K36me3 for genes of high transcript level, and CS2 enriched of H3K27me3, often associated with genes of low transcript level, both CS concerning the euchromatin [60].

In our histone PTMs analysis of total chromatin, the quantitative modifications of H3K4me3 and H3K36me3 were reduced by more than 30\% in the VvMSA-RNAi cell lines. This partial depletion of both histone marks argues in favor of a relative reduction in actively transcribed genes in VvMSA-silenced cells under normal growth. H3K4me3, as the most studied methylation mark in abiotic stress conditions, has been proposed as responsible for a memory effect during repeated stress exposure [62]. Furthermore, the dynamics of $\mathrm{H} 3 \mathrm{~K} 4 \mathrm{me} 2$ and $\mathrm{H} 3 \mathrm{~K} 4 \mathrm{me} 3$ enrichment have already been observed at the promoter region and the first exon of some immunity genes triggered by pathogen molecular patterns (WRKY53, FRK1 and NHL10) after priming with mild abiotic stresses (i.e., heat, cold, salt) [63]. It seems therefore enticing to deduce that the depletion of grape ASR, which is strongly involved in plant stress responses, may affect the stability of multiprotein complexes responsible for chromatin remodeling.

H3K9me2, described as a feature of silent transposable elements and other repeats of repressive heterochromatin, has been associated with DNA methylation and appears characteristic for the chromatin state 3 [60]. H3K9me2 has been lost in tomato roots under drought conditions [64]. Inversely, in our HPTM analysis of total chromatin H3K9me2 displayed a nearly two-fold increase, with collective significance for all RNAi lines (A, B, C) and their technical replicates in comparison to the wild-type control (Figure 6B). This sig- 
nificant enrichment of $\mathrm{H} 3 \mathrm{~K} 9 \mathrm{me} 2$ mark might suggest sustained silencing of transposons in the absence of stress-responsive VvMSA protein. In Arabidopsis seedlings subjected to heat stress, a copia-type retrotransposon named ONSEN has turned not only transcriptionally active, but also has generated novel stress-responsive regulatory genes [65]. Activation of another transposon named Athila leads to the production of small RNAs that in turn regulate expression of a key gene involved in stress tolerance [66]. Taken together with our results on $\mathrm{H} 3 \mathrm{~K} 9 \mathrm{me} 2$, these examples of reactivated transposable elements highlight a novel putative role of VvMSA in the reduced grape cell responsiveness to abiotic stresses.

Eventually, H4K16ac was detected only in the wild-type cell line expressing VvMSA, while this histone mark was not observed in the three independently transformed $V v M S A$ RNAi cell lines. Studies in yeast, Arabidopsis and rice have already revealed differential functions for the acetylation at this specific position, lysine 16 of histone H4 [67,68]. Hyperacetylation of H4K16 in budding yeast has appeared to be involved in the stability of heterochromatin boundaries and the high-order compaction of chromatin [69]. In Arabidopsis and rice, $\mathrm{H} 4 \mathrm{~K} 16 \mathrm{ac}$ has been mostly enriched around the transcription start site, and its combined effect with H3K23ac has been suggested as critical for tissue-specific and developmental regulation of gene expression [70].

ASR proteins are expressed at the transition between different stages of plant development (such as seed germination, leaf senescence, fruit ripening), and each of these transitions is subject to strong epigenetic control [71]. Consequently, we may speculate the possible involvement of ASRs as molecular chaperones/transcription factors in these epigenetically regulated events. Another argument in favor of this hypothesis has been provided by the finding that rice ASR5 is not only able to recognize binding sites upstream of the microRNA gene (MIR167a), but also to drive its expression in vivo [36]. As microRNAs are key actors of gene expression that guide post-transcriptional control of plant development and responses to environmental stresses, and as microRNA genes have been identified as preferential targets of epigenetic regulation [72], it could be suggested that ASR proteins are involved in epigenetic regulation of gene expression.

\section{Materials and Methods}

\subsection{Cell Culture and Transformation Conditions}

The grapevine embryogenic cell line 41B was obtained from the most commonly used rootstock in the vineyards of Champagne (a hybrid between Vitis vinifera L. cv. Chasselas $\times$ Vitis berlandieri P.). The embryogenic cell suspension was subcultured every two weeks by transferring $0.3 \mathrm{~mL}$ of packed cell volume into $25 \mathrm{~mL}$ of a half-strength MS medium (Duchefa M0232) containing glycerol $\left(4.6 \mathrm{G} \cdot \mathrm{L}^{-1}\right)$ and maltose $\left(18 \mathrm{~g} \cdot \mathrm{L}^{-1}\right)$ as carbon sources, as well as naphthoxyacetic acid $\left(1 \mathrm{mg} \cdot \mathrm{L}^{-1}\right)$ and casein acid hydrolysate (Sigma A2427). They were cultured under constant agitation $(110 \mathrm{rpm})$, in darkness and at $21^{\circ} \mathrm{C}$. In order to silence the grape ASR gene (VvMSA), 41B embryogenic cells were transformed with the 35S::VvMSA-RNAi construct via Agrobacterium tumefaciens strain EHA 105, coculture of the grape $41 \mathrm{~B}$ cells with the bacteria, for $60 \mathrm{~h}$ on the above-mentioned solid medium, and selection of transformed cells on paromomycin $\left(2 \mu \mathrm{g} \cdot \mathrm{mL}^{-1}\right)$ [73]. The somatic embryogenesis of $41 \mathrm{~B}$ cells was induced by their subculture into the same fresh medium depleted of auxin and at $26^{\circ} \mathrm{C}$.

\subsection{Real-Time qPCR Analysis}

Reverse transcription was carried out on $1 \mu \mathrm{g}$ of DNase-treated total RNA according to manufacturer protocol (Promega, Madison, WI, USA). Real-time qPCR was performed in $15 \mu \mathrm{L}$ reaction mixture $\left(5 \mu \mathrm{L}\right.$ of 10 -fold diluted cDNA, and $10 \mu \mathrm{L}$ of GoTaq ${ }^{\circledR}$ PCR Master Mix 1X containing $0.375 \mu \mathrm{M}$ of each primer), applying the program ( 2 min at $95{ }^{\circ} \mathrm{C}$, followed by 40 cycles with $15 \mathrm{sec}$ at $95^{\circ} \mathrm{C}$ and $1 \mathrm{~min}$ at $60{ }^{\circ} \mathrm{C}$ ), and using a Realplex ${ }^{2}$ Mastercycler (Eppendorf). The grape Actin gene was used as a reference. The primer sequences of the three genes are: VvMSA F: GCATGTGTGCTTGTTGTGTAA and R: TCACAAGGACACACAGAGAGA; $V v A C T$ F: GCATCCCTCAGCACCTTCCA and R: 
AACCCCACCTCAACACATCTCC; VvLEA D-29 F: GCTTTGAACTGTCTGCCTCTT and R: CTCATTTGCGATAAGGATAAGG.

\subsection{Isolation of Nuclei and Extraction of Nuclear Proteins}

Isolation of nuclei and extraction of nuclear proteins were carried as already described [29] and detailed in Figure S3. The integrity and the enrichment of nuclei was controlled by epifluorescence microscopy after staining with Hoechst 33258 (Sigma-Aldrich, St. Louis, MO, USA). In order to yield maximum proteins and preserve their integrity, the extraction was designed to produce three consecutive fractions: $\mathrm{NaCl}$-fraction of nucleosolic proteins with $10 \mathrm{mM}$ Tris- $\mathrm{HCl}$, pH 7.5 containing $150 \mathrm{mM} \mathrm{NaCl}, \mathrm{H}_{2} \mathrm{SO}_{4}$-fraction of chromatin loosely bound proteins with $0.4 \mathrm{~N} \mathrm{H}_{2} \mathrm{SO}_{4}$, and SDS-fraction of chromatin-tightly bound proteins with $10 \mathrm{mM}$ Tris- $\mathrm{HCl}$, pH 7.5 containing $1 \%$ SDS, all supplemented with protease inhibitors as described for the nuclei extraction. After precipitation the pellets of all three fractions were subjected to successive washes, two with $96 \%$ ethanol, two with $100 \%$ acetone, and after acetone evaporation proteins were preserved at $-20^{\circ} \mathrm{C}$.

\subsection{Experimental Design, Relative Quantification of Protein Abundance and Statistics}

Four independent biological replicates from three nuclear protein fractions of wildtype and $V v M S A-R N A i$ lines were sequentially extracted. These 24 protein extracts were individually digested and labeled using iTRAQ-8plex (Figure S4). The resulting peptides were further fractionated using SCX into 8 master fractions per extraction method. The rationale for the number of samples in an iTRAQ-8plex experiment was provided by the number of labels $(n=8)$ and the comparison of two groups. The quantitative protein ratios were normalized in Mascot by the median ratio. Ratios with $p<0.05$ and fold changes $>2.0$ were considered as significant. The identified proteins were submitted to $t$-test, normalized by mean values and eventually validated by Bonferroni test.

\subsection{Protein Digestion, iTRAQ 8-Plex Labeling, and Peptide Fractionation}

iTRAQ 8-plex experiments were performed to analyze the three nuclear protein fractions ("NaCl", " $\mathrm{H}_{2} \mathrm{SO}_{4}$ ", "SDS") from four biological replicates obtained in two conditions of the embryogenic grape cell line 41B: wild-type (WT) and VvMSA-RNAi-A. Proteins reconstituted directly in $50 \mu \mathrm{L}$ of $500 \mathrm{mM}$ triethylammonium bicarbonate buffer (TEAB), $\mathrm{pH} 8.5), 50 \mu \mathrm{g}$ per sample, were used for each iTRAQ channel. Tryptic digestion ( $10 \% w / w$, sequencing-grade modified trypsin, Promega, Madison, WI, USA) and iTRAQ 8-plex labeling (SCIEX, Concord, ON, Canada) were performed according to the manufacturers' instructions $\left(16 \mathrm{~h}\right.$-trypsin digestion at $37^{\circ} \mathrm{C}$ and $2.5 \mathrm{~h}$-incubation of samples with respective iTRAQ labels). The iTRAQ labels for WT were 113, 116, 117 and 121; those for VvMSA-RNAi-114, 115, 118 and 119. After iTRAQ labeling, the samples were combined, desalted on $500 \mathrm{mg}$ SepPak $\mathrm{C}_{18}$ columns (Millipore, Billerica, MA, USA), dried in a SpeedVac concentrator (ThermoFisher Scientific, Waltham, MA USA) and subjected to peptide fractionation by strong cation exchange chromatography (SCX). The samples were injected by using an autosampler (Agilent 1100 series, Agilent Technologies, Santa Clara, CA, USA) and directly loaded onto a $2.1 \mathrm{~mm} \times 200 \mathrm{~mm}$ SCX-column (Poly-SULPHOETHYL A, $5 \mu \mathrm{m}, 300-\AA$, PolyLC, Columbia, MD, USA). The peptides were eluted at a flow rate of $0.3 \mathrm{~mL} / \mathrm{min}$ by using the following gradient: $0-10 \mathrm{~min}$, $0 \%$ solvent $\mathrm{B}, 10-50 \mathrm{~min}, 0-35 \%$ solvent $\mathrm{B} ; 50-65 \mathrm{~min}, 35-100 \%$ solvent $\mathrm{B}$. Solvent $\mathrm{A}$ contained $10 \mathrm{mM} \mathrm{KH}_{2} \mathrm{PO}_{4}$ and $25 \%$ acetonitrile and solvent $\mathrm{B}-10 \mathrm{mM} \mathrm{KH}_{2} \mathrm{PO}_{4}, 25 \%$ acetonitrile, and $0.5 \mathrm{M} \mathrm{KCl}$; the $\mathrm{pH}$ of both buffers was adjusted to less than 3 . In this way, the labeled peptides were separated into 54 fractions that were further pooled into 8 master fractions (according to the SCX spectrum) and purified using a $\mathrm{C}_{18}$ column (Sep-Pak cartridge, Waters Corporation, Milford, MA, USA). 


\subsection{Liquid Chromatography and Tandem Mass Spectrometry}

Peptide samples of the pooled 8 master fractions from previous SCX chromatography $(4 \mu \mathrm{L})$ were analyzed on an LTQ-Orbitrap Velos mass spectrometer (Thermo Fischer Scientific, Bremen, Germany) coupled to a nano-HPLC system (Eksigent Technologies, Dublin, CA, USA). The solvent compositions were $0.2 \%$ formic acid and $1 \%$ acetonitrile for channel $\mathrm{A}$ and $0.2 \%$ formic acid and $80 \%$ acetonitrile for channel B. Peptides were loaded onto an in-house made tip column $(75 \mu \mathrm{m} \times 80 \mathrm{~mm})$ packed with reverse-phase $\mathrm{C}_{18}$ material (AQ, $3 \mu \mathrm{m}, 200$ A, Bischoff $\mathrm{GmbH}$, Leonberg, Germany) and eluted (flow rate, $250 \mathrm{~nL} / \mathrm{min}$; solvent $\mathrm{B}$ gradient: from 3 to $30 \%$ in $62 \mathrm{~min}$, from 30 to $45 \%$ in $70 \mathrm{~min}$, and from 45 to $97 \%$ in $75 \mathrm{~min})$. Full-scan MS spectra $(300-1700 \mathrm{~m} / \mathrm{z}$ ) were acquired at a resolution setting of 30,000 at $400 \mathrm{~m} / \mathrm{z}$ after accumulation to a target value of $1 \times 10^{6}$. For the eight most intense signals per cycle above a threshold of 1000 , both collision-induced dissociation (CID) and higher-energy collisional dissociation spectra were acquired in a data-dependent manner. CID scans were recorded in the ion trap (settings: normalized collision energy, 35\%; maximum injection time, $50 \mathrm{~ms}$; automatic gain control, $1 \times 10^{4}$ ions). For the higher-energy collisional dissociation scans, spectra were recorded at a resolution setting of 7500 at $400 \mathrm{~m} / \mathrm{z}$ (normalized collision energy, $45 \%$; maximum injection time, $125 \mathrm{~ms}$; automatic gain control, $5 \times 10^{4}$ ions). Charge state screening was enabled and singly charged states were rejected. Precursor masses previously selected for MS/MS were excluded from further selection for $60 \mathrm{~s}$, and the exclusion window was set at $10 \mathrm{ppm}$. The maximum number of entries in the exclusion list was set at 500 . The MS-MS runs of all eight pooled master SCX fractions of the " $\mathrm{NaCl}^{\prime}$ samples and the first four pooled master SCX fractions of the " $\mathrm{H}_{2} \mathrm{SO}_{4}$ " and the "SDS" samples were analyzed in duplicates, where precursors selected in the first run were excluded from fragmentation in the second run. The exclusion list was set on a time window of $4 \mathrm{~min}$ and a mass width of $10 \mathrm{ppm}$. Orbitrap spectra were acquired using internal lock mass calibration on $m / z 429.088735$ and 445.120025 .

\subsection{Peak List Generation and Database Search}

Mascot Distiller 2.4.3.3 (Matrix Science, Boston, MA, USA) was used to generate Mascot generic format peak lists. Deisotoping and peak picking were not performed between 112.5 and $121.5 \mathrm{~m} / \mathrm{z}$ (the range containing iTRAQ reporter ions), and the higherenergy collisional dissociation and collision-induced dissociation spectra were merged by summing the two scans from the same precursor [74,75]. For each nuclear protein fraction (NaCl-nuclesolic; $\mathrm{H}_{2} \mathrm{SO}_{4}$-chromatin loosely bound; SDS-chromatin tightly bound) all relevant Mascot generic format peak lists were concatenated and searched, using Mascot Server 2.3.02 (Matrix Science), against the grape protein database of Genoscope (http:/ / www.genoscope.cns.fr/externe/GenomeBrowser/Vitis/; accessed on 1 July 2021) combined with 54,898 entries in Uniprot annotated to Vitis vinifera. That database was concatenated to its reversed decoyed FASTA database. The concatenated database contained a total of 162,488 proteins and 260 common MS contaminants. Methylthio (C), iTRAQ 8-plex labeling at the $\mathrm{N}$ terminus and lysine were set as fixed modifications, and variable modifications consisted of methionine oxidation, deamidation of asparagine and glutamine and iTRAQ 8-plex labeling of tyrosine. The isotope and impurity correction factors used for each iTRAQ label were those provided by the manufacturer. Precursor and fragment tolerances were set at $10 \mathrm{ppm}$ and $0.8 \mathrm{Da}$, respectively. The enzyme specificity was set to trypsin with an allowance of up to one missed cleavage. Using Mascot internal export scripts, the transformed Mascot DAT files into XML files were parsed with in-house scripts so that peptide sequences, scores and intensities of the individual reporter ion channels were reported. Confidently identified and quantified peptides were selected with the following filters: rank 1 (best spectra assignment), ion score, $>25$. For the estimation of the false discovery rates at protein level, the formula in Käll et. al. (2008) was applied [76]. 


\subsection{Immunoblotting Analysis}

Acid-extracted nuclear proteins $\left(\mathrm{H}_{2} \mathrm{SO}_{4}\right.$ fraction) of the four cell lines were separated by 1 D SDS-PAGE under the following conditions: $2.5 \mu \mathrm{g}$ protein load per $2.5 \mathrm{~mm}$-wide lane of $1 \mathrm{~mm}$-thick NuPAGE Novex bis-Tris 4-12\% gels/format 26 well, run in triplicate in an XCell4 SureLock ${ }^{\mathrm{TM}}$ chamber filled with MES SDS running buffer, at 200 V constant, for $34 \mathrm{~min}$, at RT. In an immediate next step, the separated proteins were submitted to Western transfer on $0.2 \mu \mathrm{m}$ nitrocellulose membrane using a Power Blotter, at $5 \mathrm{~A}$ constant/ $25 \mathrm{~V}$ limit, for $5 \mathrm{~min}$, at RT, and the quality of protein transfer was controlled by Ponceau S staining (Figure S5). The membrane was rinsed for $5 \mathrm{~min}$ in Tris-buffered saline-TBS (10 mM Tris, $150 \mathrm{mM} \mathrm{NaCl}, \mathrm{pH}$ 8.0) supplemented with Tween-20 at 0.5\% final concentration ( $0.5 \%$ TBST), blocked for 30 min with $2 \%$ TBST, rinsed in $0.05 \%$ TBST for $5 \mathrm{~min}$, incubated for $1 \mathrm{~h}$ with the primary antibody diluted in $0.5 \%$ TBST, washed three times, $10 \mathrm{~min}$ each, in $0.05 \%$ TBST, incubated for $1 \mathrm{~h}$ with the secondary peroxidaseconjugated antibody diluted in 0.5\% TBST, washed three times, 10 min each, in 0.05\% TBST, and three more times, $5 \mathrm{~min}$ each in double distilled water, immediately overlaid with an ex tempore prepared mix of equal amounts of the Western blotting detection reagents $A$ and $B$ (ECL ${ }^{\text {TM }}$ Prime, Amersham, Chicago, IL, USA; ref. RPN2232), at final volume $0.1 \mathrm{~mL} / \mathrm{cm}^{2}$, incubated for $5 \mathrm{~min}$, in darkness. All steps were carried out at room temperature. After exposure in a CCD camera (Amersham Imager AI600, GE Healtcare, Buckinghamshire, UK), the obtained ECL images were analyzed by using the software ImageQuant TL (GE Healthcare, Buckinghamshire, UK). The ECL signal intensity of each band was quantified after background subtraction and the raw quantitative data were directly exported for further statistical analysis by unpaired $t$-test using GraphPad Prism, Version 5. The data were visualized in a heatmap generated by the Morpheus software (https:/ / software.broadinstitute.org/morpheus; accessed on 1 May 2021). References of PAGE and WB materials, user manuals, list of antibodies and their working dilutions are provided in Tables S1 and S2.

\subsection{In Silico Protein Analysis}

In silico protein analysis was performed by using tools for multiple sequence alignment (CLUSTAL O(1.2.4); https:/ / www.ebi.ac.uk/Tools/msa/clustalo/; accessed on 1 May 2021), prediction of the intrinsically disordered regions (MoRFpred; http:/ / biomine. cs.vcu.edu/servers/MoRFpred/; accessed on 1 May 2021) [77], and protein-protein interaction and functional enrichment (STRING: (Search Tool for the Retrieval of InteractiNG Genes/Proteins) https:/ / string-db.org/; accessed on 1 May 2021).

\section{Conclusions}

In our pertinent model of grape embryogenic cells, the silencing of $V v M S A$ by RNAinterference strongly impacts the nuclear proteome as revealed by iTRAQ-detected DEPs involved in epigenetic, transcriptional and post-transcriptional regulation, metabolism, cell proliferation and stress responses. The spectacular up-regulation of VvLEA D-29 protein in VvMSA-depleted cells, as well as their contrasted responsiveness to auxin depletion, implies a possible compensatory relationship of these IDPs. The demonstration that VvMSA repression differentially affects several members of distinct multiprotein and nucleoprotein structures, such as chromatin and its remodeling complexes, spliceosome, processome and ribosomes, argues in favor of a plausible role of grape ASR as a recruiting and/or stabilizing factor. Our data on the post-translational modifications of histones $\mathrm{H} 3$ and H4 in grape ASR-depleted cells corroborate the idea of VvMSA involvement in plant response to developmental and environmental cues through modulation of the epigenetic landscape.

Supplementary Materials: The following are available online at https:/ / www.mdpi.com/article/10 $.3390 /$ ijms23031537/s1.

Author Contributions: R.A. conceived the project. J.P., C.A., J.V., T.S., H.A. and R.A. performed the experiments. R.A., H.A., J.G. and B.R. carried out the data analysis and interpretation. R.A. and 
H.A. wrote the manuscript, with input from B.R. and J.G. All authors have read and agreed to the published version of the manuscript.

Funding: The work was supported by PRIME-XS funded under the 7th Framework Program of the European Union (Contract no. 262067 PRIME-XS), a PhD grant to JP from the "Région PoitouCharentes" and EPIDEP grant of the French national program on grapevine decline.

Institutional Review Board Statement: Not applicable.

Informed Consent Statement: Not applicable.

Data Availability Statement: The mass spectrometry proteomics data have been deposited to the ProteomeXchange Consortium via the PRIDE [1] partner repository with the dataset identifier PXD004988 and nul.

Acknowledgments: We are grateful to Enrico Martinoia from the University of Zurich and Joelle Roche from the University of Poitiers for their kind support, Paolo Nanni from the FGCZ for his help in the LS-MS/MS experiments, Cécile Gaillard for the regeneration of grape transgenic plantlets, Florence Thibault for help in microscopy, and the trainees Guillaume Cornut and Vianney Souday for having participated in bioinformatic analyses.

Conflicts of Interest: The authors declare no conflict of interest.

\section{References}

1. Iusem, N.D.; Bartholomew, D.M.; Hitz, W.D.; Scolnik, P.A. Tomato (Lycopersicon esculentum) transcript induced by water deficit and ripening. Plant Physiol. 1993, 102, 1353-1354. [CrossRef] [PubMed]

2. Schneider, A.; Salamini, F.; Gebhardt, C. Expression patterns and promoter activity of the cold-regulated gene ci21A of potato. Plant Physiol. 1997, 113, 335-345. [CrossRef] [PubMed]

3. Wang, C.S.; Liau, Y.E.; Huang, J.C.; Wu, T.D.; Su, C.C.; Lin, C.H. Characterization of a desiccation-related protein in lily pollen during development and stress. Plant Cell Physiol. 1998, 39, 1307-1314. [CrossRef] [PubMed]

4. de Vienne, D.; Leonardi, A.; Damerval, C.; Zivy, M. Genetics of proteome variation for QTL characterization: Application to drought-stress responses in maize. J. Exp. Bot. 1999, 50, 303-309. [CrossRef]

5. Vaidyanathan, R.; Kuruvilla, S.; Thomas, G. Characterization and expression pattern of an abscisic acid and osmotic stress responsive gene from rice. Plant Sci. 1999, 140, 21-30. [CrossRef]

6. Jeanneau, M.; Gerentes, D.; Foueillassar, X.; Zivy, M.; Vidal, J.; Toppan, A.; Perez, P. Improvement of drought tolerance in maize: Towards the functional validation of the Zm-Asr1 gene and increase of water use efficiency by over-expressing C4-PEPC. Biochimie 2002, 84, 1127-1135. [CrossRef]

7. Liu, H.Y.; Dai, J.R.; Feng, D.R.; Liu, B.; Wang, H.B.; Wang, J.F. Characterization of a novel plantain Asr gene, MpAsr, that is regulated in response to infection of Fusarium oxysporum f. sp. cubense and abiotic stresses. J. Integr. Plant Biol. 2010, 52, 315-323. [CrossRef]

8. Arenhart, R.A.; Lima, J.C.; Pedron, M.; Carvalho, F.E.; Silveira, J.A.; Rosa, S.B.; Caverzan, A.; Andrade, C.M.B.; Schünemann, M.; Margis, R.; et al. Involvement of ASR genes in aluminium tolerance mechanisms in rice. Plant Cell Environ. 2013, $36,52-67$. [CrossRef]

9. Medici, A.; Laloi, M.; Atanassova, R. Profiling of sugar transporter genes in grapevine coping with water deficit. FEBS Lett. 2014, 588, 3989-3997. [CrossRef]

10. Huang, K.; Zhong, Y.; Li, Y.; Zheng, D.; Cheng, Z.M. Genome-wide identification and expression analysis of the apple ASR gene family in response to Alternaria alternata f. sp. mali. Genome 2016, 59, 866-878. [CrossRef]

11. Cakir, B.; Agasse, A.; Gaillard, C.; Saumonneau, A.; Delrot, S.; Atanassova, R. A grape ASR protein involved in sugar and ABA signaling. Plant Cell 2003, 15, 2165-2180. [CrossRef] [PubMed]

12. Kalifa, Y.; Gilad, A.; Konrad, Z.; Zaccai, M.; Scolnik, P.A.; Bar-Zvi, D. The water-and salt-stress-regulated Asr1 (abscisic acid stress ripening) gene encodes a zinc-dependent DNA-binding protein. Biochem. J. 2004, 381, 373-378. [CrossRef]

13. Wang, H.J.; Hsu, C.M.; Jauh, G.Y.; Wang, C.S. A lily pollen ASR protein localizes to both cytoplasm and nuclei requiring a nuclear localization signal. Physiol. Plant. 2005, 123, 314-320. [CrossRef]

14. Ricardi, M.M.; Guaimas, F.F.; González, R.M.; Burrieza, H.P.; López-Fernández, M.P.; Jares-Erijman, E.A.; Estévez, J.M.; Iusem, N.D. Nuclear import and dimerization of tomato ASR1, a water stress-inducible protein exclusive to plants. PLoS ONE 2012, 7, e41008. [CrossRef] [PubMed]

15. Arenhart, R.A.; Schunemann, M.; Bucker Neto, L.; Margis, R.; Wang, Z.Y.; Margis-Pinheiro, M. Rice ASR1 and ASR5 are complementary transcription factors regulating aluminium responsive genes. Plant Cell Environ. 2016, 39, 645-651. [CrossRef]

16. Hsu, Y.F.; Yu, S.C.; Yang, C.Y.; Wang, C.S. Lily ASR protein-conferred cold and freezing resistance in Arabidopsis. Plant Physiol. Biochem. 2011, 49, 937-945. [CrossRef] 
17. Konrad, Z.; Bar-Zvi, D. Synergism between the chaperone-like activity of the stress regulated ASR1 protein and the osmolyte glycine-betaine. Planta 2008, 227, 1213-1219. [CrossRef]

18. Frankel, N.; Nunes-Nesi, A.; Balbo, I.; Mazuch, J.; Centeno, D.; Iusem, N.D.; Fernie, A.R.; Carrari, F. ci21A/Asr1expression influences glucose accumulation in potato tubers. Plant Mol. Biol. 2007, 63, 719-730. [CrossRef]

19. Dominguez, P.G.; Frankel, N.; Mazuch, J.; Balbo, I.; Iusem, N.; Fernie, A.R.; Carrari, F. ASR1 mediates glucose-hormone cross talk by affecting sugar trafficking in tobacco plants. Plant Physiol. 2013, 161, 1486-1500. [CrossRef]

20. Saumonneau, A.; Laloi, M.; Lallemand, M.; Rabot, A.; Atanassova, R. Dissection of the transcriptional regulation of grape ASR and response to glucose and abscisic acid. J. Exp. Bot. 2012, 63, 1495-1510. [CrossRef]

21. Fàbregas, N.; Fernie, A.R. The interface of central metabolism with hormone signaling in plants. Curr. Biol. 2021, 31, R1535-R1548. [CrossRef] [PubMed]

22. Battaglia, M.; Olvera-Carrillo, Y.; Garciarrubio, A.; Campos, F.; Covarrubias, A.A. The enigmatic LEA proteins and other hydrophilins. Plant Physiol. 2008, 148, 6-24. [CrossRef] [PubMed]

23. Goldgur, Y.; Rom, S.; Ghirlando, R.; Shkolnik, D.; Shadrin, N.; Konrad, Z.; Bar-Zvi, D. Desiccation and zinc binding induce transition of tomato abscisic acid stress ripening 1 , a water stress- and salt stress-regulated plant-specific protein, from unfolded to folded state. Plant Physiol. 2007, 143, 617-628. [CrossRef] [PubMed]

24. Dai, J.R.; Liu, B.; Feng, D.R.; Liu, H.Y.; He, Y.M.; Qi, K.B.; Wang, H.B.; Wang, J.F. MpAsr encodes an intrinsically unstructured protein and enhances osmotic tolerance in transgenic Arabidopsis. Plant Cell Rep. 2011, 30, 1219-1230. [CrossRef]

25. Hamdi, K.; Salladini, E.; O’Brien, D.P.; Brier, S.; Chenal, A.; Yacoubi, I.; Longhi, S. Structural disorder and induced folding within two cereal, ABA stress and ripening (ASR) proteins. Sci. Rep. 2017, 7, 15544. [CrossRef]

26. Wright, P.E.; Dyson, H.J. Intrinsically unstructured proteins: Re-assessing the protein structure-function paradigm. J. Mol. Biol. 1999, 293, 321-331. [CrossRef]

27. Uversky, V.N.; Gillespie, J.R.; Fink, A.L. Why are "natively unfolded" proteins unstructured under physiologic conditions? Proteins 2000, 41, 415-427. [CrossRef]

28. Romero, P.; Obradovic, Z.; Li, X.; Garner, E.C.; Brown, C.J.; Dunker, A.K. Sequence complexity of disordered protein. Proteins 2001, 42, 38-48. [CrossRef]

29. Uversky, V.N. What does it mean to be natively unfolded? Eur. J. Biochem. 2002, 269, 2-12. [CrossRef]

30. Tompa, P. Intrinsically unstructured proteins. Trends Biochem. Sci. 2002, 27, 527-533. [CrossRef]

31. Maskin, L.; Frankel, N.; Gudesblat, G.; Demergasso, M.J.; Pietrasanta, L.I.; Iusem, N.D. Dimerization and DNAbinding of ASR1, a small hydrophilic protein abundant in plant tissues suffering from water loss. Biochem. Biophys. Res. Commun. 2007, 352, 831-835. [CrossRef] [PubMed]

32. Saumonneau, A.; Agasse, A.; Bidoyen, M.T.; Lallemand, M.; Cantereau, A.; Medici, A.; Laloi, M.; Atanassova, R. Interaction of grape ASR proteins with a DREB transcription factor in the nucleus. FEBS Lett. 2008, 582, 3281-3287. [CrossRef] [PubMed]

33. Yoon, J.S.; Seo, Y.W. BdERF96 interacts with BdASR1 to specifically respond to drought and oxidative stress in Brachypodium distachyon. J. Plant Biochem. Biotechnol. 2021, 30, 287-296. [CrossRef]

34. Ricardi, M.M.; González, R.M.; Zhong, S.; Domínguez, P.G.; Duffy, T.; Turjanski, P.G.; Salter, J.D.S.; Alleva, K.; Carrari, F.; Gionvannoni, J.J.; et al. Genome-wide data (ChIP-seq) enabled identification of cell wall-related and aquaporin genes as targets of tomato ASR1, a drought stress-responsive transcription factor. BMC Plant Biol. 2014, 14, 29. [CrossRef]

35. Zhang, L.; Hu, W.; Wang, Y.; Feng, R.; Zhang, Y.; Liu, J.; Jia, C.; Miao, H.; Zhang, J.; Xu, B.; et al. The MaASR gene as a crucial component in multiple drought stress response pathways in Arabidopsis. Funct. Integr. Genom. 2015, 15, 247-260. [CrossRef]

36. Neto, L.B.; Arenhart, R.A.; de Oliveira, L.F.; de Lima, J.C.; Bodanese-Zanettini, M.H.; Margis, R.; Margis-Pinheiro, M. ASR5 is involved in the regulation of miRNA expression in rice. Plant Cell Rep. 2015, 34, 1899-1907. [CrossRef]

37. Arenhart, R.A.; Bai, Y.; de Oliveira, L.F.; Neto, L.B.; Schunemann, M.; Maraschin Fdos, S.; Mariath, J.; Silverio, A.; Sachetto-Martins, G.; Margis, R.; et al. New insights into aluminum tolerance in rice: The ASR5 protein binds the STAR1 promoter and other aluminumresponsive genes. Mol. Plant 2014, 7, 709-721. [CrossRef]

38. Gilad, A.; Amitai-Zeigerson, H.; Bar-Zvi, D.; Scolnik, P.A. Asr1, a tomato water-stress regulated gene: Genomic organization, developmental regulation and DNA-binding activity. Acta Hortic. 1997, 447, 441-453. [CrossRef]

39. Marín, M.; Ott, T. Intrinsic disorder in plant proteins and phytopathogenic bacterial effectors. Chem. Rev. 2014, 114, 6912-6932. [CrossRef]

40. Candat, A.; Paszkiewicz, G.; Neveu, M.; Gautier, R.; Logan, D.C.; Avelange-Macherel, M.H.; Macherel, D. The ubiquitous distribution of late embryogenesis abundant proteins across cell compartments in Arabidopsis offers tailored protection against abiotic stress. Plant Cell 2014, 26, 3148-3166. [CrossRef] [PubMed]

41. Rom, S.; Gilad, A.; Kalifa, Y.; Konrad, Z.; Karpasas, M.M.; Goldgur, Y.; Bar-Zvi, D. Mapping the DNA- and zinc-binding domains of ASR1 (abscisic acid stress ripening), an abiotic-stress regulated plant specific protein. Biochimie 2006, 88, 621-628. [CrossRef] [PubMed]

42. Leung, J.; Gaudin, V. Who Rules the Cell? An Epi-Tale of Histone, DNA, RNA, and the Metabolic Deep State. Front. Plant Sci. 2020, 11, 181. [CrossRef] [PubMed]

43. Morimoto, T.; Suzuki, Y.; Yamaguchi, I. Effects of partial suppression of ribosomal protein S6 on organ formation in Arabidopsis thaliana. Biosci. Biotechnol. Biochem. 2002, 66, 2437-2443. [CrossRef] 
44. Deprost, D.; Yao, L.; Sormani, R.; Moreau, M.; Leterreux, G.; Nicolaï, M.; Bedu, M.; Robaglia, C.; Meyer, C. The Arabidopsis TOR kinase links plant growth, yield, stress resistance and mRNA translation. EMBO Rep. 2007, 8, 864-870. [CrossRef] [PubMed]

45. Reinbothe, C.; Pollmann, S.; Reinbothe, S. Singlet oxygen signaling links photosynthesis to translation and plant growth. Trends Plant Sci. 2010, 15, 499-506. [CrossRef] [PubMed]

46. Mahfouz, M.M.; Kim, S.; Delauney, A.J.; Verma, D.P.S. Arabidopsis TARGET OF RAPAMYCIN interacts with RAPTOR, which regulates the activity of $S 6$ kinase in response to osmotic stress signals. Plant Cell 2006, 18, 477-490. [CrossRef]

47. Yang, C.; Zhang, C.; Dittman, J.D.; Whitham, S.A. Differential requirement of ribosomal protein S6 by plant RNA viruses with different translation initiation strategies. Virology 2009, 390, 163-173. [CrossRef]

48. Wang, J.; Lan, P.; Gao, H.; Zheng, L.; Li, W.; Schmidt, W. Expression changes of ribosomal proteins in phosphate- and iron-deficient Arabidopsis roots predict stress-specific alterations in ribosome composition. BMC Genom. 2013, 14, 783. [CrossRef]

49. Parrilla, J.; Gaillard, C.; Verbeke, J.; Maucourt, M.; Aleksandrov, R.A.; Thibault, F.; Fleurat-Lessard, P.; Gibon, Y.; Rolin, D.; Atanassova, R. Comparative metabolomics and glycolysis enzyme profiling of embryogenic and nonembryogenic grape cells. FEBS Open Bio 2018, 8, 784-798. [CrossRef]

50. Dirk, L.M.A.; Abdel, C.G.; Ahmad, I.; Neta, I.C.S.; Pereira, C.C.; Pereira, F.E.C.B.; Unêda-Trevisoli, S.H.; Pinheiro, D.G.; Downie, A.B. Late embryogenesis abundant protein-client protein interactions. Plants 2020, 9, 814. [CrossRef]

51. Ibrahime, M.; Kibar, U.; Kazan, K.; Özmen, C.Y.; Mutaf, F.; Aşçi, S.D.; Çakir Aydemir, B.; Ergül, A. Genome-wide identification of the LEA protein gene family in grapevine (Vitis vinifera L.). Tree Genet. Genomes 2019, 15, 55. [CrossRef]

52. Ferron, F.; Longhi, S.; Canard, B.; Karlin, D. A practical overview of protein disorder prediction methods. Proteins-Struct. Funct. Bioinform. 2006, 65, 1-14. [CrossRef] [PubMed]

53. Longhi, S.; Lieutaud, P.; Canard, B. Conformational disorder. Meth. Mol. Biol. 2010, 609, 307-325. [CrossRef]

54. Lieutaud, P.; Ferron, F.; Longhi, S. Predicting Conformational Disorder. Meth. Mol. Biol. 2016, 1415, 265-299. [CrossRef]

55. Wise, M.J.; Tunnacliffe, A. POPP the question: What do LEA proteins do? Trends Plant Sci. 2004, 9, 13-17. [CrossRef]

56. Chen, Y.; Li, C.; Zhang, B.; Yi, J.; Yang, Y.; Kong, C.; Lei, C.; Gong, M. The role of the Late Embryogenesis-Abundant (LEA) protein family in development and the abiotic stress response: A comprehensive expression analysis of potato (Solanum tuberosum). Genes 2019, 10, 148. [CrossRef]

57. Ding, Y.; Liu, N.; Virlouvet, L.; Riethoven, J.J.; Fromm, M.; Avramova, Z. Four distinct types of dehydration stress memory genes in Arabidopsis thaliana. BMC Plant Biol. 2013, 13, 229. [CrossRef]

58. Zhang, K.; Sridhar, V.V.; Zhu, J.; Kapoor, A.; Zhu, J.K. Distinctive core histone posttranslational modification patterns in Arabidopsis thaliana. PLoS ONE 2007, 2, e1210. [CrossRef]

59. Lauria, M.; Rossi, V. Epigenetic control of gene regulation in plants. Biochim. Biophys. Acta 2011, 1809, 369-378. [CrossRef]

60. Roudier, F.; Ahmed, I.; Bérard, C.; Sarazin, A.; Mary-Huard, T.; Cortijo, S.; Bouyer, D.; Caillieux, E.; Duvernois-Berthet, E.; Al-Shikhley, L.; et al. Integrative epigenomic mapping defines four main chromatin states in Arabidopsis. EMBO J. 2011, 30, 1928-1938. [CrossRef]

61. Sani, E.; Herzyk, P.; Perrella, G.; Colot, V.; Amtmann, A. Hyperosmotic priming of Arabidopsis seedlings establishes a long-term somatic memory accompanied by specific changes of the epigenome. Genome Biol. 2013, 14, R59. [CrossRef] [PubMed]

62. Asensi-Fabado, M.A.; Amtmann, A.; Perrella, G. Plant responses to abiotic stress: The chromatin context of transcriptional regulation. Biochim. Biophys. Acta Gene Regul. Mech. 2017, 1860, 106-122. [CrossRef] [PubMed]

63. Lämke, J.; Brzezinka, K.; Altmann, S.; Bäurle, I. A hit-and-run heat shock factor governs sustained histone methylation and transcriptional stress memory. EMBO J. 2016, 35, 162-175. [CrossRef]

64. González, R.M.; Ricardi, M.M.; Iusem, N.D. Epigenetic marks in an adaptive water stress-responsive gene in tomato roots under normal and drought conditions. Epigenetics 2013, 8, 864-872. [CrossRef]

65. Ito, H.; Gaubert, H.; Bucher, E.; Mirouze, M.; Vaillant, I.; Paszkowski, J. An siRNA pathway prevents transgenerational retrotransposition in plants subjected to stress. Nature 2011, 472, 115-119. [CrossRef]

66. McCue, A.D.; Nuthikattu, S.; Reeder, S.H.; Slotkin, R.K. Gene expression and stress response mediated by the epigenetic regulation of a transposable element small RNA. PLoS Genet. 2012, 8, e1002474. [CrossRef] [PubMed]

67. Shia, W.J.; Pattenden, S.G.; Workman, J.L. Histone H4 lysine 16 acetylation breaks the genome's silence. Genome Biol. 2006, 7, 217. [CrossRef]

68. Vaquero, A.; Sternglanz, R.; Reinberg, D. NAD+-dependent deacetylation of H4 lysine 16 by class III HDACs. Oncogene 2007, 26, 5505-5520. [CrossRef]

69. Shogren-Knaak, M.; Ishii, H.; Sun, J.M.; Pazin, M.J.; Davie, J.R.; Peterson, C.L. Histone H4-K16 acetylation controls chromatin structure and protein interactions. Science 2006, 311, 844-847. [CrossRef]

70. Lu, L.; Chen, X.; Sanders, D.; Qian, S.; Zhong, X. High-resolution mapping of H4K16 and H3K23 acetylation reveals conserved and unique distribution patterns in Arabidopsis and rice. Epigenetics 2015, 10, 1044-1053. [CrossRef]

71. Zhao, T.; Zhan, Z.; Jiang, D. Histone modifications and their regulatory roles in plant development and environmental memory. J. Genet. Genom. 2019, 46, 467-476. [CrossRef] [PubMed]

72. Shaik, R.; Ramakrishna, W. Bioinformatic analysis of epigenetic and microRNA mediated regulation of drought responsive genes in rice. PLoS ONE. 2012, 7, e49331. [CrossRef] 
73. Coutos-Thévenot, P.; Poinssot, B.; Bonomelli, A.; Yean, H.; Breda, C.; Buffard, D.; Esnault, R.; Hain, R.; Boulay, M. In vitro tolerance to Botrytis cinerea of grapevine 41B rootstock in transgenic plants expressing the stilbene synthase Vst1 gene under the control of a pathogen-inducible PR 10 promoter. J. Exp. Bot. 2001, 52, 901-910. [CrossRef] [PubMed]

74. Uzozie, A.; Nanni, P.; Staiano, T.; Grossmann, J.; Barkow-Oesterreicher, S.; Shay, J.W.; Tiwari, A.; Buffoli, F.; Laczko, E.; Marra, G. Sorbitol dehydrogenase overexpression and other aspects of dysregulated protein expression in human precancerous colorectal neoplasms: A quantitative proteomics study. Mol. Cell. Proteom. 2014, 13, 1198-1218. [CrossRef]

75. Barkow-Oesterreicher, S.; Türker, C.; Panse, C. FCC - An automated rule-based processing tool for life science data. Source Code Biol. Med. 2013, 8, 3. [CrossRef]

76. Käll, L.; Storey, J.D.; MacCoss, M.J.; Noble, W.S. Assigning significance to peptides identified by tandem mass spectrometry using decoy databases. J. Proteome Res. 2008, 7, 29-34. [CrossRef] [PubMed]

77. Disfani, F.M.; Hsu, W.L.; Mizianty, M.J.; Oldfield, C.J.; Xue, B.; Dunker, A.K.; Uversky, V.N.; Kurgan, L. MoRFpred, a computational tool for sequence-based prediction and characterization of short disorder-to-order transitioning binding regions in proteins. Bioinformatics 2012, 28, i75-i83. [CrossRef] 